\title{
Comparison of Variability of the Monthly Mean Temperature of the ECMWF and NCEP Reanalyses and CCM3 and CSM Simulations
}

\author{
J.S. Boyle
}

Lawrence

Livermore

National

Laboratory

February 23, 2000 


\section{DISCLAIMER}

This document was prepared as an account of work sponsored by an agency of the United States Government. Neither the United States Government nor the University of California nor any of their employees, makes any warranty, express or implied, or assumes any legal liability or responsibility for the accuracy, completeness, or usefulness of any information, apparatus, product, or process disclosed, or represents that its use would not infringe privately owned rights. Reference herein to any specific commercial product, process, or service by trade name, trademark, manufacturer, or otherwise, does not necessarily constitute or imply its endorsement, recommendation, or favoring by the United States Government or the University of California. The views and opinions of authors expressed herein do not necessarily state or reflect those of the United States Government or the University of California, and shall not be used for advertising or product endorsement purposes.

Work performed under the auspices of the U. S. Department of Energy by the University of California Lawrence Livermore National Laboratory under Contract W-7405-Eng-48.

This report has been reproduced directly from the best available copy.

Available to DOE and DOE contractors from the

Office of Scientific and Technical Information

P.O. Box 62, Oak Ridge, TN 37831

Prices available from (423) 576-8401

http://apollo.osti.gov/bridge/

Available to the public from the National Technical Information Service

U.S. Department of Commerce 5285 Port Royal Rd., Springfield, VA 22161 http://www.ntis.gov/

OR

Lawrence Livermore National Laboratory Technical Information Department's Digital Library http://www.llnl.gov/tid/Library.html 


\title{
Comparison of Variability of the Monthly Mean Temperature of the ECMWF and NCEP Reanalyses and CCM3 and CSM Simulations
}

\author{
by \\ James S. Boyle \\ Program for Climate Model Diagnosis and Intercomparison \\ Lawrence Livermore National Laboratory \\ Livermore, CA USA
}

Wednesday, February 23, 2000

March 2000 


\begin{abstract}
The low frequency variation in the three dimensional air temperature fields of two reanalyses and two model simulations are described The data sets used are the monthly mean temperature fields for the NCAR Climate Simulation Model (CSM, Boville and Gent, 1998) 300 year run, a NCAR Community Climate Model version 3 (CCM3, Kiehl et al., 1998) AMIP type simulation, and the NCEP/NCAR and ECMWF (ERA) reanalysis data sets. The variances and correlations are computed for the anomalies from the annual cycle for each data set.

In general the reanalyses and models agree fairly well on the structure of the temperature variance. The models tend to have too much variance at the surface compared to the reanalyses. The CSM's poor simulation of the SST in the eastern Pacific leads to a much reduced variance in the Nino3 region. The cnhanced variability over land appears to affect the midlatitude simulation of the CSM in that the higher surface variability extends off the east coast of continents. This is not evident in CCM3 and reanalyses where the SSTs are prescribed.

At $200 \mathrm{hPa}$ the CCM3 and reanalyses all evince the dumb bell pattern straddling the Equator in the eastern Pacific attributed by Yulaeva and Wallace (1994) to ENSO variations. The CSM shows no such pattern. A CCM3 integration using climatological SSTs displays more variance that the CSM in this region, apparently the CSM supresses variability in this locale.

The correlations of the temperature fields with the surface air temperature show that the regions of subtropical subsidence are virtually uncorrelated to the surface at the $700 \mathrm{hPa}$ level. The regions of the cold water off the west coast of continents evince decoupling with the surface at $850 \mathrm{hPa}$. In the region from $30 \mathrm{~S}$ to $30 \mathrm{~N}$ the zonal mean correlation falls to about 0.7 below $800 \mathrm{hPa}$, with this value extending up to about 600 $\mathrm{hPa}$ in mid and upper latitudes. These characteristics are consistent across all the data sets. Thus, the variations of vertically integrated measures such as MSU tempertures do not need agree with observations of surface air temperatures at the time scales examined here.
\end{abstract}




\section{Introduction}

The purpose of this paper is to describe aspects of the low frequency variation in the three dimensional air temperature fields of two reanalyses and two model simulations. The primary data are monthly means. This aspect of the data restricts the definition of the highest frequencies as those passed by the monthly mean filtering process. The annual cycle is removed from the data, so that the interannual variations are the result. The data sets used are the temperature fields for the NCAR Climate Simulation Model (CSM, Boville and Gent, 1998) 300 year run, a NCAR Community Climate Model version 3 (CCM3, Kiehl et al., 1998) AMIP type simulation, and the NCEP/NCAR and ECMWF (ERA) reanalysis data sets.

The motivation for looking at the three dimensional structure of temperature variance originally came from a consideration of the problem of reconciling observed surface temperature and Microwave Sounding Unit (MSU) records. Many aspects of the comparsion of these two data records were described in detail by Hurrel and Trenberth $(1992,1998)$. These works described how the variations of the surface and MSU records are not of neccessity the same. Their interest was to describe physical, instrumental and practical reasons why the decadal temperture trends differed. The origin and significance of these discrepancies are the source of debate in the arena of the detection of global warming. In the present work, we merely are examining the structures found in the variance data with a view towards understanding their origins and perhaps documenting the more unusual features.

The two model data sets include a coupled atmospheric and ocean simulation and a prescribed SST integration with the same atmospheric model being used in both integrations. Recently, some interest has arisen as to the differences between such simulations, Blade (1997, 1999) and Barsugli and Battisti (1998). These studies focus on the impact of specifying the SST field on very extended integrations. Blade finds that coupling does not modify the spatial organization of the variability, but is does cause a significant enhancemant of the lower tropopsheric thermal variance over the oceans at very low frequencies. The uncoupled integration in this study is not long enough, 13 years, to resolve the low frequencies depicted by Blade. The tact taken here is to try and describe differences in the temperature variance attributable to the difference in coupling. There is an addtional problem in that the coupled simulation produces an ENSO signal in the ocean of about $60 \%$ of the amplitude observed, Meehl 
and Arblaster (1998). This confounds the comparision since the atmospheric model in the uncoupled simulation is being forced by tropical SST anomalies somewhat larger than those produced by the coupled simulation.

Hurrel et al. (1998) and Boville and Hurrel (1998) show that the CCM3 produces a very reasonable climatology compared to the observations and that the CSM and CCM3 agree closely on most aspects of the atmospheric circulation. Meehl and Arblaster (1998) carry out a close examination of the Asian/Australian monsoon and the ENSO in this CSM integration. They show the model represents most of the major features of the monsoon system and its connections of the tropical Pacific. A time series of the NINO-3 region indicates that the CSM is producing about $60 \%$ of the amplitude of the observed interannual oceanic variability. Moreover, the correlations globally with these regions reproduce the main features of the observed variations accompanying ENSO. The CSM displays its largest amplitude ENSO SST anomalies in the western tropical Pacific compared to the observed SST variability maximum in the central and eastern tropical Pacific. This paper is not intended to be a study of the ENSO events in the CSM, but by considering the dominant modes of longer time scale variation in the observations and models the ENSO takes center stage, especially in comparing to the observations in the years since 1979 .

Yulaeva and Wallace (1994) focus on the signature of ENSO events on the temperture fields derived from the MSU. They identified a equatorially symmetric dumbell shaped pattern over the western Pacific. This pattern was shown to fluctuate in response to displacements of the convective activity over the equatorial Pacific which are related to the SST anaomalies. The dumbell pattern is associated with the upper tropospheric gyres that are a dynamical response to shifts in the distribution of diabatic heating in the equatorial Pacific. Thus, this pattern in the temperture variance at the upper levels $(-200 \mathrm{hpa})$ is an important indicator of the ability of a model to capture the full dynamics of the ENSO anomalies.

In the next section the reanalyses data sets will be described, followed by a description of the model data. The next two sections compare the interannual variance. Finally, there will be a section on conclusions.

\section{Data and data procedures}

a. Re-analyses 
Reanalyses data are available from two sources. The first is the NCEP/NCAR reanalyses described by Kalnay et al. (1996). These data are provided on a $2.5 \times 2.5$ degree longitude latitude grid and consist of monthly means from 1958 to 1996 . The second set is the ECMWF Reanalysis (ERA) described by Gibson et al.(1997). These data are also on a $2.5 \times 2.5$ degree grid and are monthly means spanning the period form 1979 to 1993. Both the reanalyses are an attempt to eliminate the problem of changing data analysis systems which plagued the operational data sets. Both reanalyses ingest approximately the same observational data and the assimilation models are forced by nearly identical SSTs. Although the reanalyses have constant assimilation systems they both suffer from a changing observational network, as stations change and as different remote sensing data are introduced. These changes in input data are convolved with the natural variability making estimates of 'true' variability uncertain.

b. Models

The CSM is described by Boville and Gent (1998). The CCM3 is the atmospheric component of the CSM and is described by Kiehl et al. (1998).

The CCM3 simulation data used is for the period 1979 through 1993 using the Reynold's SSTs after November 1982. The SSTs prescribed for the CCM3 run are monthly means of the data used by the NCEP reanalysis system. The CSM data is from the 300 year run, Kiehl et al. (1998). Starting at year 16, the CSM run is sampled for 20 year intervals, to facilitate comparison to available reanalyses, and to assess the modes of variability in these time scales. Where all the 20 year chunks exhibit essentially similar behavior, the 16-35 period will be used, since this period is described by Meehl and Arblaster (1998). A control integration was performed with the CCM3 in which the SSTs specified were the climatolgical values for the 12 months of the year generated from the SSTs from 1979 to 1993. This integration was run for a length of 10 years.

\section{Results}

\section{a. Standard Deviations}

Figure 1 displays the standard deviation of the monthly mean anomalies of the surface air temperature. The figure displays the results for all months of the year. Examination of the individual seasons, DJF, JJA, MAM, JJA, show that at the higher 
latitudes the wintertime variance dominates the annual pattern whilst the Tropics are not as seasonally dominated. The Northern Hemisphere displays the largest seasonal asymmetry. The full year data are presented since they do not obscure any of the points being made, and allow for a succinct presentation. The prominent features in the higher latitudes are almost wholly attributable to wintertime variations.

Figure 1 clearly shows that the land has far more variance in these time scales than the ocean regions. The region of the eastern equatorial Pacific most affected by the El Niño displays a tongue of enchanced variance extending from South America in the reanalyses and CCM3. The ERA evinces a much stronger signal in the ENSO region compared to the NCEP. The CSM misses this ENSO related feature and has only a weak region of variability in the western equatorial Pacific. The CSM also has a distinctly different field over the north Pacific, with a rather prominent maximum near $165 \mathrm{~W}, 40 \mathrm{~N}$. The reanalyses and CCM3 show a weak corridor of maximum values extending from the Asian east coast at about $45 \mathrm{~N}$. The CSM has somewhat higher values over the ocean in the northern Pacific, this results in a reduced gradient from ocean to land epecially in the region of the Kamchatka Peninsula. This behaviour is not evident at any other of the ocean poleward margins and might bc related to the serious sea ice problems in the northern Pacific, Weatherly et al. (1998). Since the same SSTs were prescribed for the ERA, NCEP and CCM3, it is expected that they would display close agreement over the oceans. The models tend to have a higher variance over land compare to the reanalyses. This is especially evident over North America and Asia. This results in the models having stronger gradients at the coasts as they relax towards variance values similar to the reanalyses over the oceans.

Figure 2 is the same as Fig, 1, except for the $850 \mathrm{hPa}$ level. At this level the high values are not as concentrated over the land as they were for the surface air temperature. The regions of cold upwelling off the west coasts of the continents emerge as oceanic high variance locations. The correspondence amongst the reanalyses and CCM3 is fairly close. As with the surface fields the models tend to have larger values over land. The ERA has a greater variance in the Fquatorial East Pacific extending over western South America. The CSM also matches the other fields if one ignores the lack of variability in the equatorial East Pacific. In the midlatitude northern Pacific, the region of higher variance extends farther equatorward from the basin edge in the CSM compared to the others. This appears to be more widespread than might to attributable to the sea ice problem. Both the CSM and CCM3 have a broader region of 
high gradients over the east ooasts of Asia and North America, the variance in interior of these continents being substantially larger in the models and the gradients more closely conform to the coastlines than in the observations.

At $300 \mathrm{hPa}$, Fig. 3, the variance tends to have bands of maxima along 30 North and South. The CSM has a closer correspondence with the two reanalyses along the equatorward flank on the Tibetan Plateau than the CCM3. However, the CSM has little evidence of the bridge of high variance across the Tropics from 150 to $120 \mathrm{~W}$. Except for the CSM the other data sets have values of variance on the Equator comparable to those found in the subtropics, $(30 \mathrm{~N}, \mathrm{~S})$ across this region. This is a manifestation of the dumbell shaped pattern identified by Yulaeva and Wallace (1994), asociated with ENSO driven anomalies. The ERA and NCEP have a maxmimum of variance just east of the Kamchatka Peninsula, this is only weakly seen in the models.

Figure 4 presents the surface, 850 and $300 \mathrm{hPa}$ standard deviation of temperature for the CCM3 integration with climatological SSTs. Fig. 4a, the surface air temperature variance, shows a much reduced variability over the oceans compared to Fig. 1, but not zero. Over the land Fig. 4a closely resembles the values generated by the CCM3 and CSM. This would indicate that the variations over land do not have a dominant contribution from the ocean variability on these time scales. The low variation over the sea leads to very strong gradients from land to sea, especially in the mid and higher latitudes. At $850 \mathrm{hPa}$, Fig. 4b, the climatological run looks much like the CCM3, ERA and NCEP, outside ot the Tropical Pacific. Evidently, the ENSO signal does not have a dramatic impact for this level so its nonappearance in the climatolgical SSTs does not have a very adverse effect on the global scale. The maxima in variance in the equatorial eastern Pacific at the $300 \mathrm{hPa}$ level is captured weakly by this integration. Evidently, even with climatological SST's, there is enough variation in the Tropical heating to produce a hint of the dumbell pattern. Given the data in Figs. $4 \mathrm{~b}, \mathrm{c}$, it would appear that the endemic cold water along the Equator in the CSM acts to supress some tropical variance that occurs in the CCM3 even in the absence of SST variability. Figure 4 also illustrates that the patterns of variability on these time scales are set by processes additional to the El Nino cycle. The climatological run is perhaps most different at $300 \mathrm{hPa}$, Fig. 4c, from the CCM3.

To provide a more comprehensive vertical picture, the next set of figures present some longitude, pressure slices along various latitudes. Figure 5 presents the standard deviation of temperature for a longitude, pressure section along the Equator. 
Over the El Nino region in the eastern Pacific there are prominent maxima at low levels and at $300 \mathrm{hPa}$ for the CCM3 and reanalyses. All three show an elevated maxima at low levels near 210E. The NCEP maxima are overall somewhat weaker than the CCM3 and ERA and especially so over South America. . The CSM has a weak surface maxima shifted to the west at $150 \mathrm{E}$ and a very weak upper level maximum at 300 $\mathrm{hPa}$. Both the CSM and CCM3 evince activity near $240 \mathrm{E}$ at about $700 \mathrm{hPa}$, which are not seen in the observations. Their surface maxima is larger then the reanalyses over the maritime continent.

Figure 6 is the same as Fig. 5 except along 15N. The maximum at $300 \mathrm{hPa}$ at about $210 \mathrm{E}$ corresponding to the feature seen in the Equatorial plot is present in the reanalyses and CCM3 but again absent in the CSM. There is a pattern of enhanced variance extending upward and westward from the regions of maximum variance at the surface along the east coastlines over the oceans. The CSM has variance levels at the surface across the Pacific comparable to the other three. Above the surface the CSM has generally less variability, although this is a somewhat more so for the ERA and CCM3. Both model integrations have larger land values than either reanalyses. Along 15S, Fig. 7, the plume of variance extending upward and westward from the east coasts of continents is even more obvious. it is especially prominent in the ERA figure. The CCM3 and CSM tend to resemble the ERA. The activity at $300 \mathrm{hPa}$ is symmetric about the Equator as expected from Fig. 3 and the results of Yulaeva and Wallace (1994).

Figure 8 moves the analysis into the midlatitudes, displaying the variance along $45 \mathrm{~N}$. At these latitudes the variance is not just dominated by the surface and lower troposphere values but there is considerable activity aloft. Over the Pacific in the reanalyses, there is a pattern whereby the maximum of variance arches upward from near the surface at the east coast of Asia reaches a maxima over the ocean at $500 \mathrm{hPa}$. and then descends to the west coast of North America. There is a similar pattern over the Atlantic, but the maximum over the ocean only goes up to about $800 \mathrm{hPa}$. The CCM3 captures this pattern over the Pacific, although it has an anomalously large maximum near $120 \mathrm{E}$ at $900 \mathrm{hPa}$. Over the Atlantic, the high values over North America seem to extend over the ocean, producing a gradient across the ocean but no distinct elevated maximum. The CSM has the same strong maximum on the east Asian coast as the CCM 3 and pushes the low level high values halfway across the ocean. The excessive activity along the coast may be held in check the the specified SSTs in the 
CCM3 but the ocean interaction within the CSM may allow this variability to spread eastward. Above $600 \mathrm{hPa}$ the CCM3 and CSM agree quite closely.

Figure 9 are longitude, level sections for the CCM3 climatological integration for the Equator, $15 \mathrm{~N}, 15 \mathrm{~S}$ and $45 \mathrm{~N}$, analogous to Figs. 5, 6, 7, and 8. Figure 9a, the Equatorial section, has almost as much variance as the NCEP renalyses over the Nino 3 region. The elevated maximum at $210 \mathrm{E}$ and the maximum at $300 \mathrm{hPa}$ both key ENSO signatures are missing in Fig. 9a as they are in the CSM data. Figure 9a displays the same maximum at about $700 \mathrm{hPa}$ as the models in Fig. 5, this is evidently a feature of the CCM3 atmospheric model independent of SST variability. The sections at $15 \mathrm{~N}$, S, Figs. 9b,c, are more similar to the reanalyses than the CSM, if one ignores the missing variance peaking at about $300 \mathrm{hPa}$. In midlatitudes, Fig. 9d, the climatological SST run very closely resembles the CCM3. At these time scales and at this latitude the SST makes no egregious impact on the model atmospheric variability. The sections at $15 \mathrm{~N}, \mathrm{~S}$ and $45 \mathrm{~N}$ are quite similar in the CCM 3 and climatological simulations, except that the maximum at $300 \mathrm{hPa}$ in the $15 \mathrm{~N}, \mathrm{~S}$ seen in the CCM3 are not present in the climatological run. .

Figure 10 is the variance from pole to pole along $225 \mathrm{E}$. This is the position of the dumbell pattern of variance about the Equator at $300 \mathrm{hPa}$. There is an deep minimum of variance in the Tropics and indications of local minima in the subtropics, especially near $30 \mathrm{~S}$. There is a layer of minimum values just below the tropopause such that the upper Tropical values are comparable to those farther poleward in all the data except for the CSM. The most striking difference in the CSM is that the Tropics. (15N,S) maintains a distinct minimun to $100 \mathrm{hPa}$. At about $300 \mathrm{hPa}$ the other three models have minima in the Tropics comparable to the midlatitudes poleward to $50 \mathrm{~N}, \mathrm{~S}$. This is peculiar to the region about this longitude as can be seen in Fig. 3. At longitudes away from $225 \mathrm{E}$, the other data sets have vertical structure much like CSM at this longitude. The climatological CCM3 , Fig. 11, has a structure that is similar to the CSM in that the Tropics maintain their singularly low values up to the top. Figure 11 does show that the climatological integration has somewhat larger incursions of high variance into the Tropics around the 800 to $700 \mathrm{hPa}$ levels, some hint of this tendency is seen in the CCM3 data, Fig. 10c.

b. Correlations with height

As indicated at the onset of this work, part of the motivation for looking at the temperature structure was to reconcile the apparent differences between the MSU 
lower tropospheric temperatures and the surface air temperatures. One aspect of describing the relation between these two measures is to examine the correlation between the surface air temperature and the temperature at height. In the following section, some investigation is made using the correlation as to the relation of the surface air temperature with the overlying layers.

Figure 12 presents the correlation coefficient between the surface air temperature and the $850 \mathrm{hPa}$ temperature. The values over land for the most part exceed 0.9. The regions of cold ocean water off the west coasts of continents have low values, becoming negative in the ERA and CSM. The ERA and especially the CCM3 have patpattterns evidently related to those of the ENSO SST's. A tongue of high values along the Equatorial Pacific projecting from South America, and flanking low values poleward on the west side of the Pacific. The anomalous cold water in the model along the Equator accounts for the low values in the CSM Equatorial Pacific. The ERA and NCEP do have some evident differences, the ERA displaying a great deal more structure over the oceanic regions and generally having greater values for this region.

The correlations of surface air temperature and the $500 \mathrm{hPa}$ temperature, Fig. 13, display an even more distinctive ENSO pattern for all the data, save the CSM. The CSM does share many features in common with the other data sets once outside of the Tropics. The ERA has very prominent bands of negative values flanking the deep Tropics, almost all around the globe. A distinctive local feature common to all the data sets, is the minimum on the East Asian coast over southern China.

Figure 14 is a longitude-pressure section along $15 \mathrm{~N}$ of the correlation of air temperature at pressure levels with the surface temperature. The tight gradient to lower values over the Pacific basin is slightly lower in the ERA compared to NCEP, over the Atlantic they appear similar. The CCM3 generally has a more rapid falloff with height than the CSM, in this respect the CSM is like NCEP, the CCM3 like ERA. The region from $60 \mathrm{E}$ to $90 \mathrm{E}$ crosses the Indian subcontinent. The NCEP data show a less dramatic transition in passing from the land to the bounding seas. All the data sets display different behavior across the Pacific Basin from $100 \mathrm{E}$ to $270 \mathrm{E}$. The relationship between the surface air temperature and the lowest $200 \mathrm{hPa}$ over this region is different in the CCM3 and CSM. Although both models achieve similar correlation values by $700 \mathrm{hPa}$.

Figure 15 a longitude-pressure section along $30 \mathrm{~N}$ of the correlation of air temperature at pressure levels with the surface temperature. In general regions over land 
have higher values extending farther upward, over the oceans the correlations drop off quite rapidly with height. In the mid-Pacific the 0.6 value is reached at $\sim 800 \mathrm{hPa}$. There are prominent fingers of mimimum values pointing down towards the west coasts of the continents. Another profile of minimum values is located just to the east of the Tibetan Plateau over southern China. Here the effect might be that of the upstream blocking by the mountains allowing the upper and lower levels to decouple. The agreement between the data sets is somewhat better at this latitude than at the $15 \mathrm{~N}$ of the previous figure. The climatological data, Fig. 16, resembles all the other sets, indicating that the major features of this section are not driven by SST variability alone. Figure 17 is the zonal mean of the correlations of surface air temperature and temperature at each pressure level. This is an attempt to give a global perspective on how well the temperature anomalies at height are related to the surface values. In a linear model the correlation of 0.7 corresponds explaining $49 \%$ of the variance. For must of the globe, except for the high northern latitudes this value of correlation coefficient is located below $700 \mathrm{hPa}$. On might then anticipate that on a global basis the surface and levels above the boundary layer need not vary in synchrony.

\section{c. Low Pass standard deviation}

Since the ENSO type signal was prominent in the fields, the next figures present the variance computed after a low pass filter was applied to the data. The filter was similar of that of Trenberth (1992) designed to pass variations of time scale greater than 8 months. The impact of this filtering is to greatly reduce the variance over land, although the qualitative patterns remain intact from the unfiltered data, Fig. 1. In view of this just the surface fields will be shown since the remainder would be rather redundant.

Figure 18 is the standard deviation of the low pass monthly mean anomaly of surface air temperature. The pattern is generally the same as Fig. 1, the variance of the unfiltered surface air temperature. The difference between the land and water has decreased with the levels of the variance over the land being somewhat less in Fig. 17. The variability of the land surface temperatures have a substantial component of periods less than 8 months. The variance in the eastern Equatorial Pacific is much the same, indicating that the bulk of the variance is in the longer (ENSO) time scales. The CCM3 maintains steep gradients on the northern edge of the Pacific, and along Antarctica. In both observational sets this gradient is relaxed in going from Figs. 1 to 18 . In the northern Atlantic the gradient is maintained across all the data 
sets. One curious fealure is the strong maxima in the CCM3 over the Central US. The numerous isolated maxima over the Northern Arctic in the NCEP data may indicate some problem with the sea ice specification. The CSM variability over the northern Pacific is distinct from other three sets.

\section{d. Power spectra}

Figure 19 presents power spectral density spectra for the surface temperature anomalies for a point at $120 \mathrm{~W}, 60$. This land location is near a maximum of variance for all the data sets. As noted above there is substantial contribution to the variance at the higher frequencies. This is especially true for the reanalyses, they evince only a small reddning. The CSM has a distincly redder spectrum from the reanalyes, perhaps partially inherited from the CCM3 since they both share the identical land surface model. As seen by the difference of variance in the central US between the CSM and CCM3 in Fig. 18, there is no guarantee that the same surface model will inevitably produce the same level of variance.

Figure 20 presents the power spectral density spectra for the surface temperature anomalies for a point at $175 \mathrm{~W}, 45 \mathrm{~N}$. This oceanic point displays a much redder spectrum than the land point of Fig. 18. The reanalyses data sets are very similar, not too surprising since they used almost identical SSTs. The CCM3 is similar to the reanalyses, it too used the same SSTs but the model does modify the surface air temperature. The low frequency component in the CCM3 does not cross the $95 \%$ significant curve, as do the NCEP and FRA. The significance levels are somewhat higher in the CCM3, and higher still in the CSM. There is evidence that the coupled models will have more power at low frequencies than the same atmopsheric GCM run with specified observed SSTs.

\section{Conclusions}

The variance structure of the temperature field of the two reanalyses agree to the extent that we can be fairly confident that the features documented here are robust. The agreement of the CCM3 is quite good, and outside the Tropics the CSM likewise shows good agreement. The ERA consistently has more variance than the NCEP with the exception of some isolated points.

The model simulations show a distinct increase in variance over land compared to the reanalyses at the lower levels. In the case of the CSM the enhanced suface vari- 
ability appears to compromise the midlatitude variance off the east coast of continents. The coupled simulation apparently allows more variation over the ocean than either the observations and CCM3 both of which operate with prescribed SSTs.

The impact of ENSO on the tropical variance of the Pacific is confined below 700 $\mathrm{hPa}$ but then reappears from about 400 to $200 \mathrm{hPa}$. Away from the Equator the signature at $300 \mathrm{hpa}$ is all that survives in the eastern Pacific in the CCM3 and reanalyses. Aloft at $200 \mathrm{hPa}$ both the reanalyses and CCM3 show the dumbell shaped pattern straddling the equator in the eastern Pacific that was related to ENSO forcing by Yulaeva and Wallace (1994). However, the CCM3 run with climatological SSTs and so lacking any ENSO, does show a modest variability in the region also. This might be related to activity across the wave duct of westerly upper level flow above the equatorial eastern Pacific. The CSM has almost no variablity in this key climatic region, despite having some ENSO variation albcit weak, Mcchl and Arblaster(1998). This would indicate that the circulation of the CSM, which is compromised by a poor ocean simulation in the tropical Pacific, actually supresses variation that the uncoupled model displays. This points to more qualitative problems than just quantitative adjustment of amplitude in the tropical simulation of the variation in temperature by the CSM.

The correlation with surface air temperture falls off rather rapidly with height, epsecially over the oceans. The correlation decreases more rapidly in the ERA than the NCEP, in both the 0.7 levels generally lies below $700 \mathrm{hPa}$

Figure 21 is the ratio variance for the surface air temperature of the CSM to the CCM3 for the lowpass data. The length of the integrations is much too short to reach any of the conclusions for Blade $(1997,1998)$ concerning the redding of the variance spectrum of coupled versus non-coupled models. This figure's most prominent features highlight the shortcomings of the CSM's tropical ocean simulation and potential problems in the sea ice model. In the Tropics, the CCM3 is variability is much greater and in the northern Oceans the CSM is slightly greater. There appears to be a slight enhancement of the variability in the northern oceans of the CSM apart from the ice edges. In the southern oceans, there is no consistent pattern. The CCM3 activity in the central US stands out as one of the more prominent land based differences. This indicates that the land surface cannot be ignored as a source of additional variability. 
Acknowledgments. The generosity of the NCAR CSM modeling group in making their data available is greatly appreciated. This work was performed under the auspices of the U. S. Department of Energy by University of California Lawrence Livermore National Laboratory under contract W-7405-ENG-48. 


\section{References}

Blade, I., 1997: The Influence of Midlatitude Ocean-Atmosphere Coupling on the Low-Frequency Variability of a GCM. Part I: No Tropical SST Forcing., J. Climate, 10, 2087-2106.

Blade, I., 1997: The Influence of Midlatitude Ocean-Atmosphere Coupling on the Low-Frequency Variability of a GCM. Part II: Interannual Variability Induced by Tropical SST Forcing., J. Climate, 10, 2087-2106.

Boville, B. A., and P. R. Gent, 1998: The NCAR Climate System Model, Version One., J. Climate, 11, 1115-1130.

Boville, B. A., and J. W. Hurrel, 1998: A comparison of the atmospheric circulations simulated by the CCM3 and CSM1., J. Climate, 11, 1327-1341.

Gibson, J. K., P. Kallberg, S. Uppla, A. Hernandez, A. Nomura, and E. Serrano, 1997: ECMWF Re-Analysis Project Report Series. 1. ERA Description. 66p.

Hurrel, J. and K. Trenberth, 1992: An evaluation of monthly mean MSU and ECMWF global atmospheric temperatures for monitoring climate., J. Climate,5,14241440.

Hurrel, J. and K. Trenberth, 1998: Difficulties in obtaining reliable temperature trends: Reconciling the surface and satellite microwave sounding unit records. J. Climate, 11, 945-967.

Hurrel, J. W. , J. J. Hack, B. A. Boville, D. L. Williamson, and J. T. Kiehl, 1998: The dynamical simulation of the NCAR Comunity Climate Model Versin 3 (CCM3). J. Climate, 11, 1207-1236.

Kalnay, E. M., M. Kanimitsu, R. Kistler, W. Collins, D. Deaven, L. Gandin, M. Iredell, S. Saha, G. White, J. Woolen, Y. Zhu, M. Chelliah, W. Ebisuzaki, W. Higgins, J. Janowiak, K. C. Mo, C. Ropelewski, J. Wang, A. Leetma, R. Reynolds, R. Jenne and D. Joseph, 1996: The NCEP/NCAR 40-year reanalysis project. Bull. Amer. Met. Soc., 77, 437-471.

Kiehl, J. T., J.J. Hack, G. B. Bonan, B.A. Boville, D. L. Williamson, and P. J. Rasch, 1998: The National Center for Atmospheric Research Community Climate Model: CCM3., J. Climate, 11, 1131-1149.

Meehl, G. A. and J. M. Arblaster, 1998: The Asian-Australian Monsoon and El Nino Southern Oscillation in the NCAR Climate System Model. J. Clim, 11, 13561385 . 
Weatherly, J. W., B. P. Briegleb, W. G. Large, and J. A. Maslanik, 1998: Sea ice and polar climate in the NCAR CSM., J. Climate, 11, 1472-1486.

Yulaeva, E. and J. M. Wallace, 1994: The signature of ENSO in global temperature and precipitation fields derived from the microwave sounding unit., J. Clim., 7, 1719-1736. 

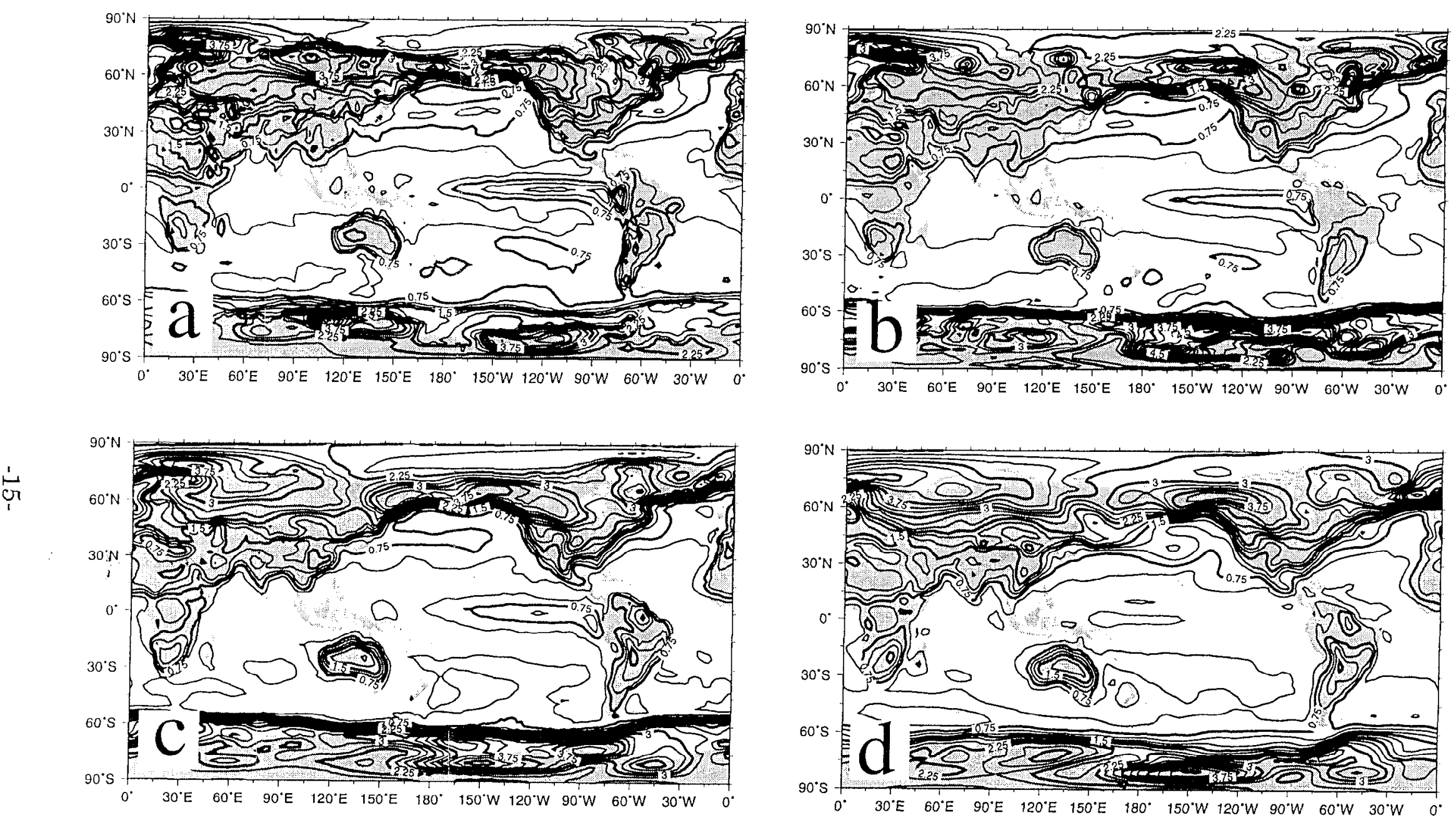

Figure 1. Standard deviation of monthly mean surface air temperature anomalies. The anomalies are defined as deviations from the annual cycle. (a) ERA, (b) NCEP/NCAR, (c) CCM3, (d) CSM. Contour interval is $0.5 \mathrm{~K}^{\circ}$. 

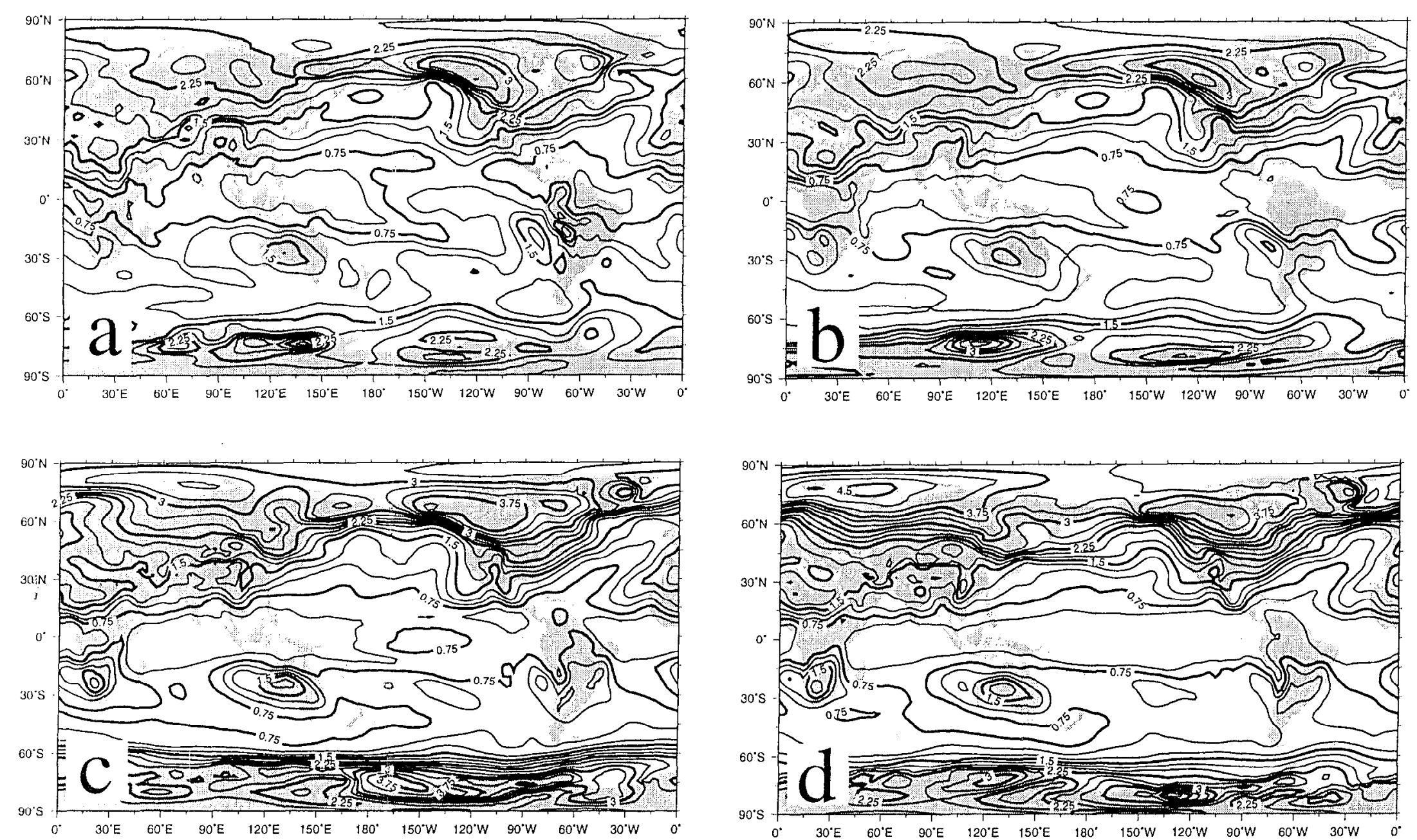

Figure 2 as in Fig. 1 except for the $850 \mathrm{hPa}$ level. (a) ERA, (b) NCEP/NCAR, (c) CCM3, (d) CSM. Contour interval is $0.5 \mathrm{~K}^{\circ}$. 

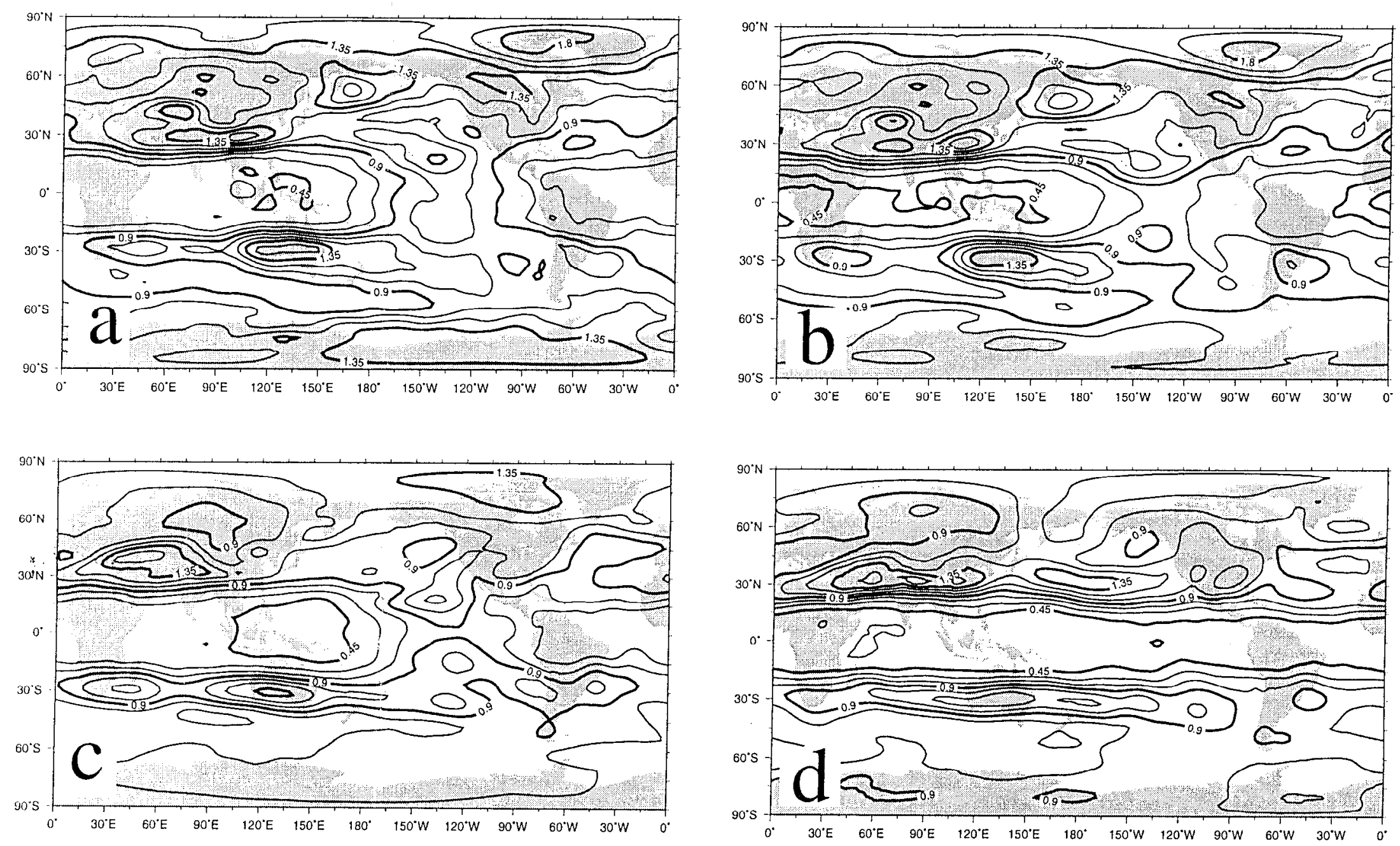

Figure 3 as in Fig. 1 except for the $300 \mathrm{hPa}$ level. (a) ERA, (b) NCEP/NCAR, (c) CCM3 , (d) CSM. Contour interval is $0.15 \mathrm{~K}^{\circ}$. 

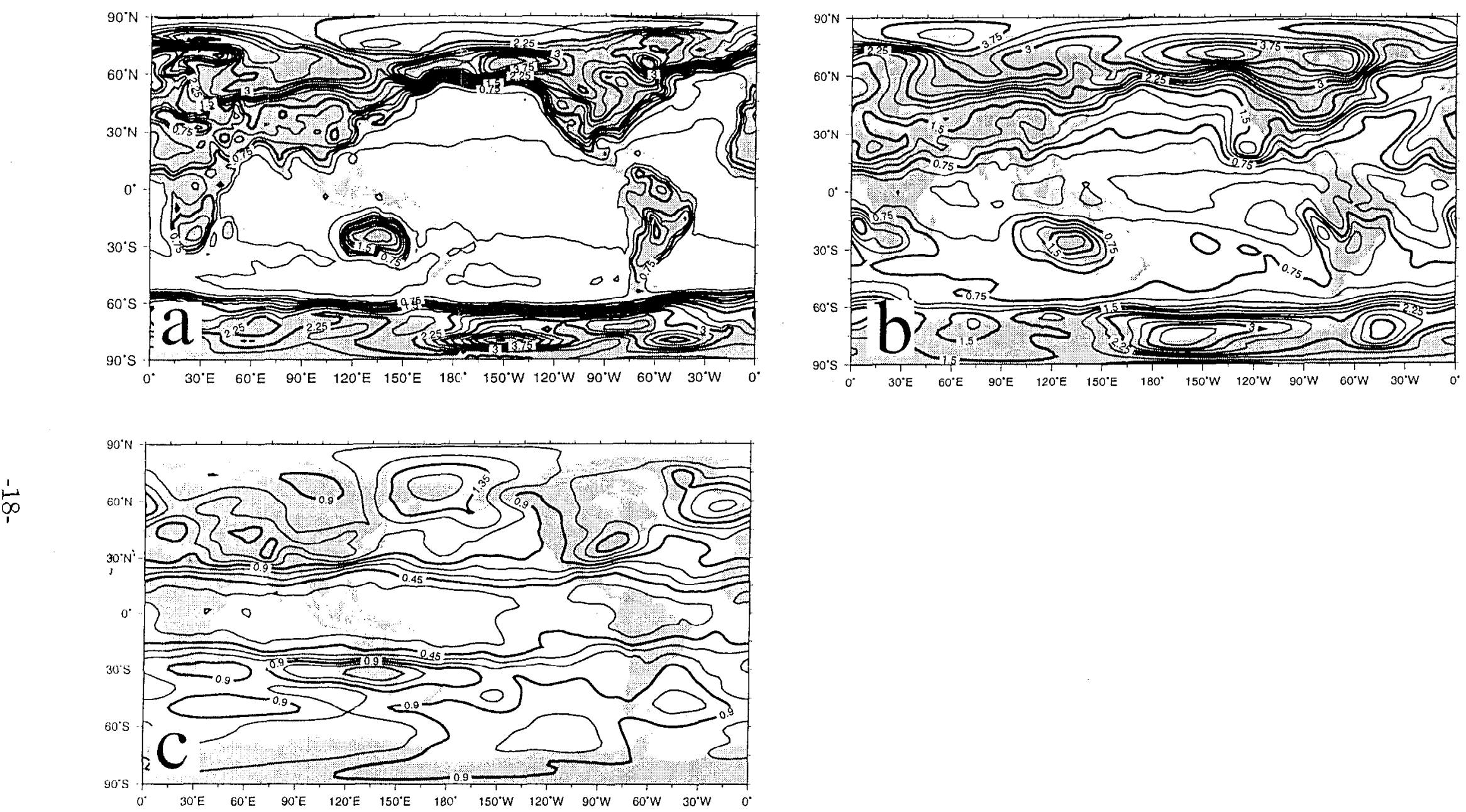

Figure 4. Standard deviation of monthly mean air temperature anomalies for the CCM3 using climatological SSTs. (a) Surface air, (b) 850 $\mathrm{hPa}$, (c) $300 \mathrm{hPa}$. The contour intervals are $0.5,0.5$ and $0.15 \mathrm{~K}^{\circ}$, respectively. 

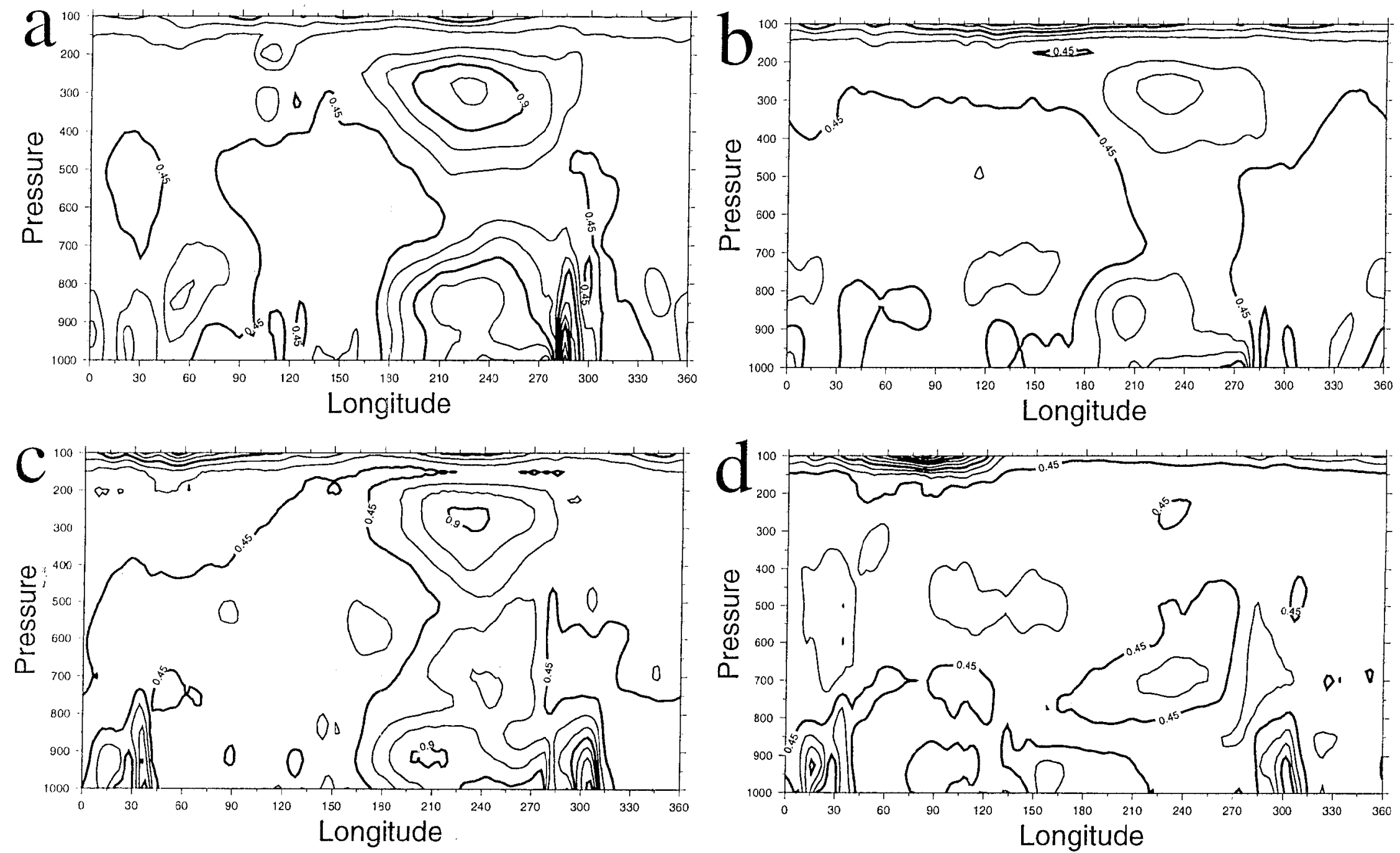

Figure 5. Standard deviation of temperature about the globe at the Equator from 1000 to $100 \mathrm{hPa}$. (a) ERA, (b) NCEP/NCAR, (c) CCM3, (d) CSM. The contour interval is $0.5 \mathrm{~K}^{\circ}$. 

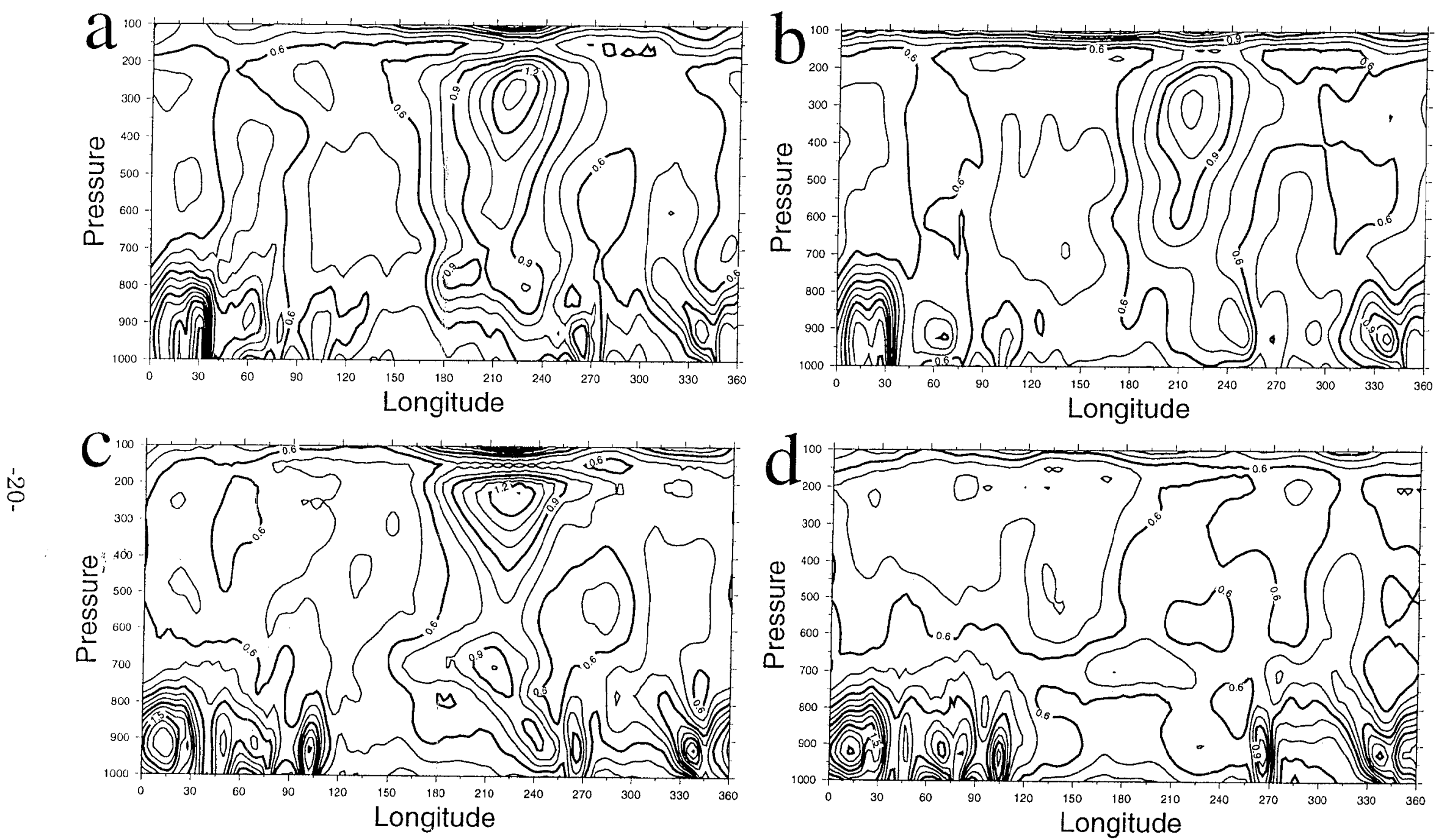

Figure 6. Standard deviation of temperature about the globe at $15^{\circ} \mathrm{N}$ from 1000 to $100 \mathrm{hPa}$. (a) ERA, (b) NCEP/NCAR, (c) CCM3 , (d) CSM. The contour interval is $0.1 \mathrm{~K}^{\circ}$. 

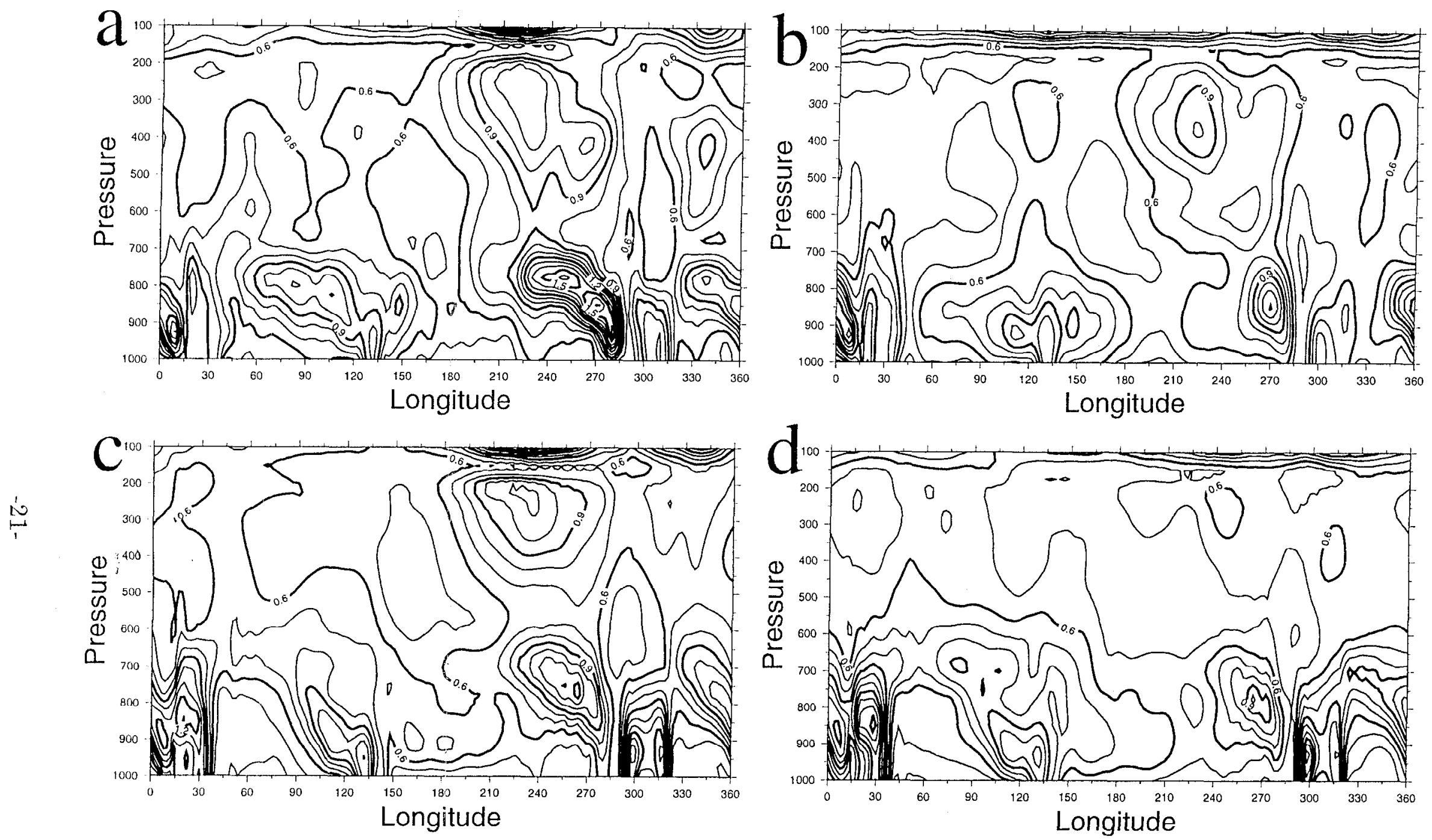

Figure 7. Standard deviation of temperature about the globe at $15^{\circ} \mathrm{S}$ from 1000 to $100 \mathrm{hPa}$. (a) ERA, (b) NCEP/NCAR, (c) CCM3, (d) CSM. The contour interval is $0.1 \mathrm{~K}^{\circ}$. 

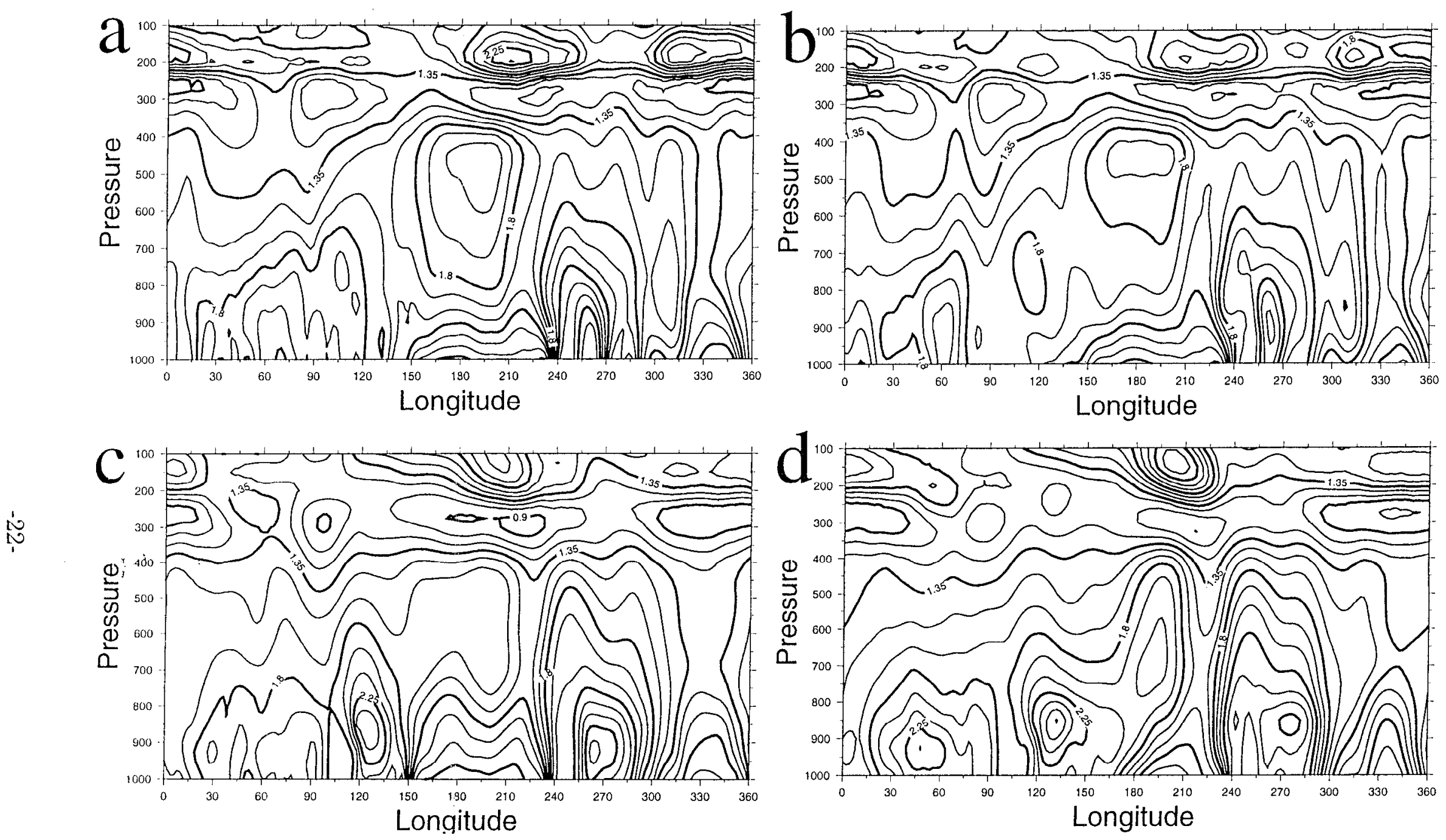

Figure 8. Standard deviation of temperature about the globe at $45^{\circ} \mathrm{N}$ from 1000 to $100 \mathrm{hPa}$. (a) ERA, (b) NCEP/NCAR, (c) CCM3 , (d) CSM. The contour interval is $0.15 \mathrm{~K}^{\circ}$ 

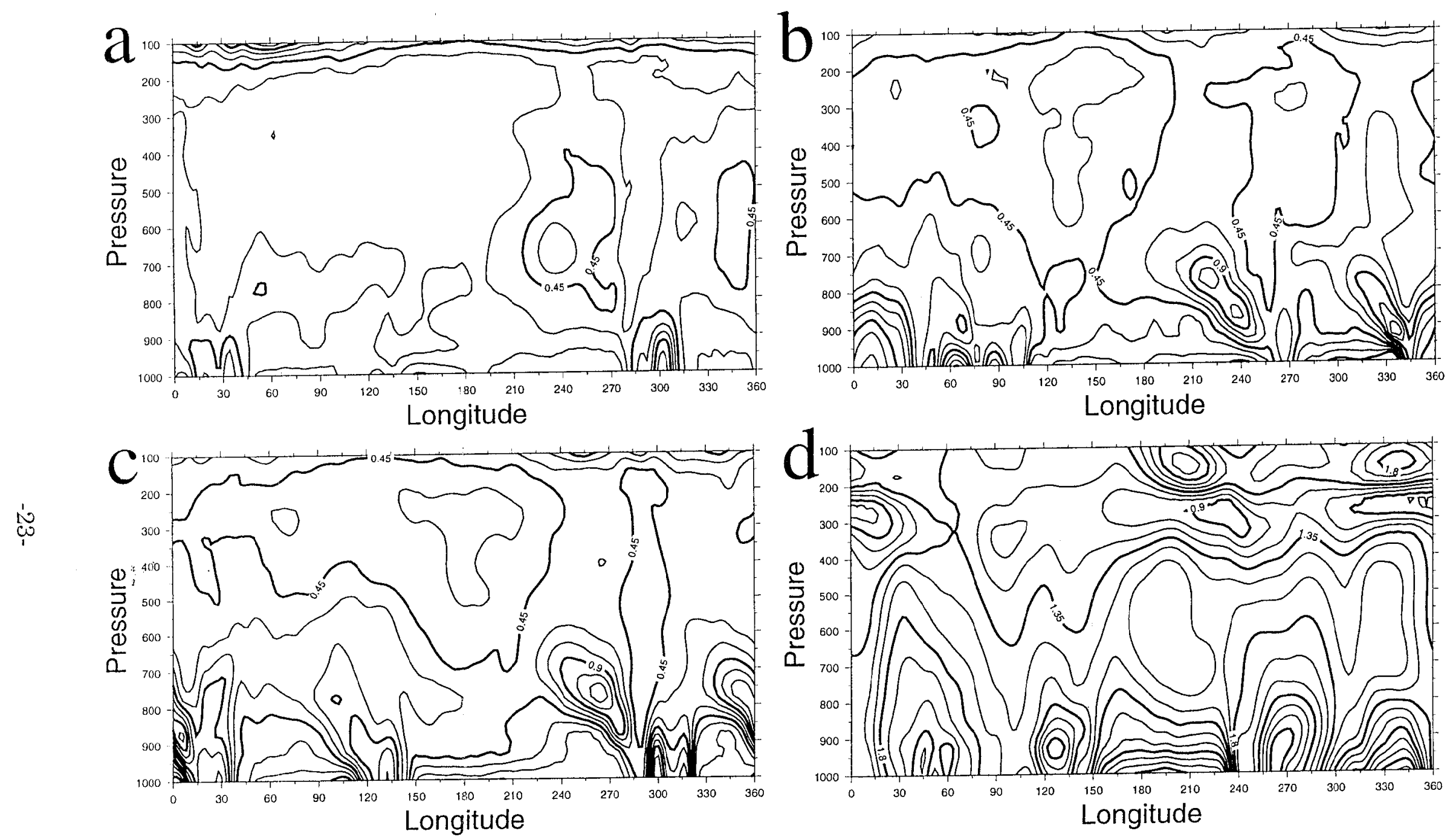

Figure 9. Standard deviation of monthly mean air temperature anomalies for the CCM3 using climatological SSTs. Pressure - Longitude sections along (a) Equator, (b) $15 \mathrm{~N}$, (c) $15 \mathrm{~S}$., (d) $45 \mathrm{~N}$. The contour intervals are $0.15 \mathrm{~K}^{\circ}$. 

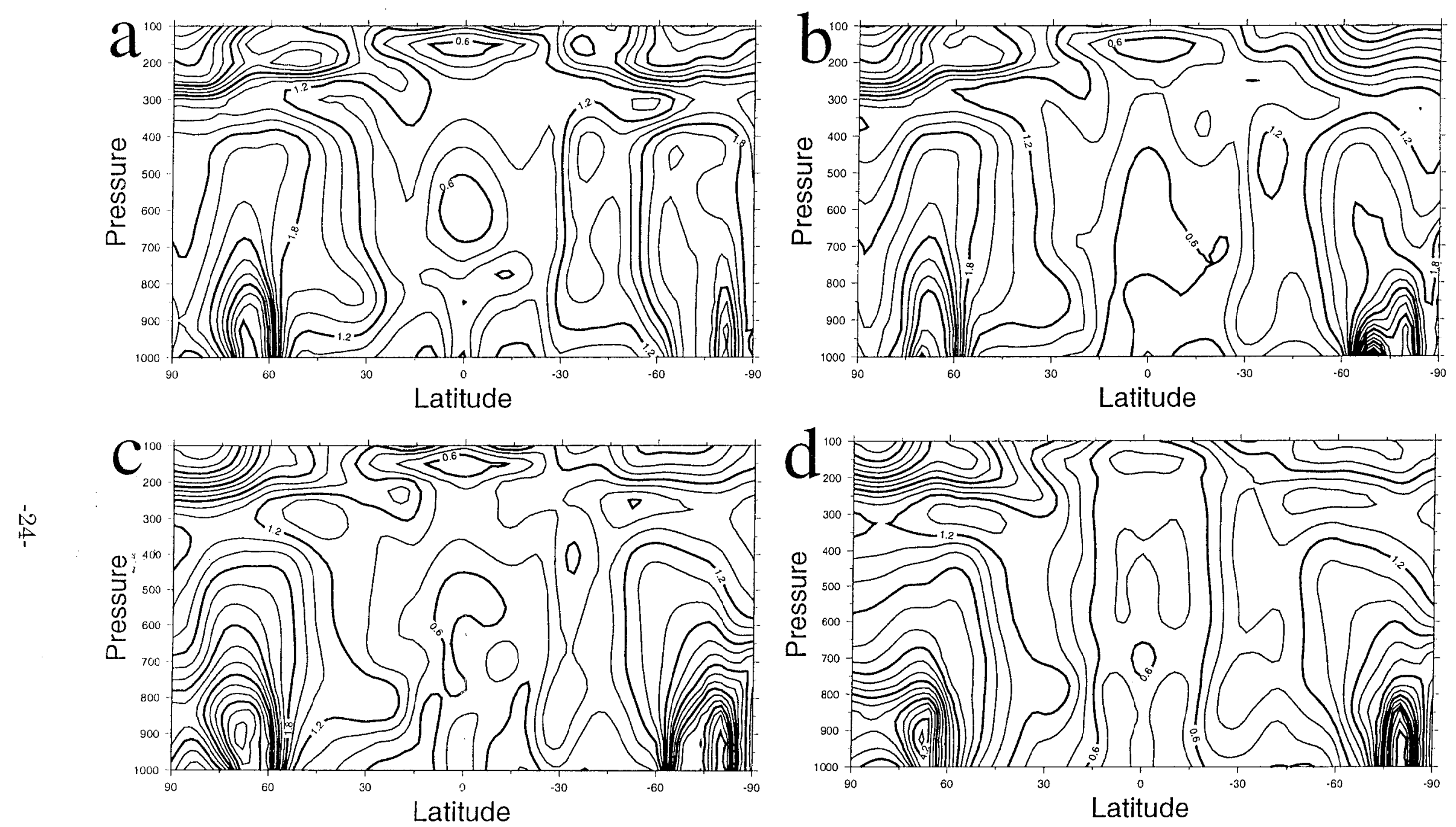

Figure 10. Standard deviation of monthly mean air temperature anomalies along longitude 225E from North to South Pole, (a) ERA, (b) NCEP/ NCAR, (c) CCM3, (d) CSM. Contour interval is $0.2 \mathrm{~K}^{\circ}$ 


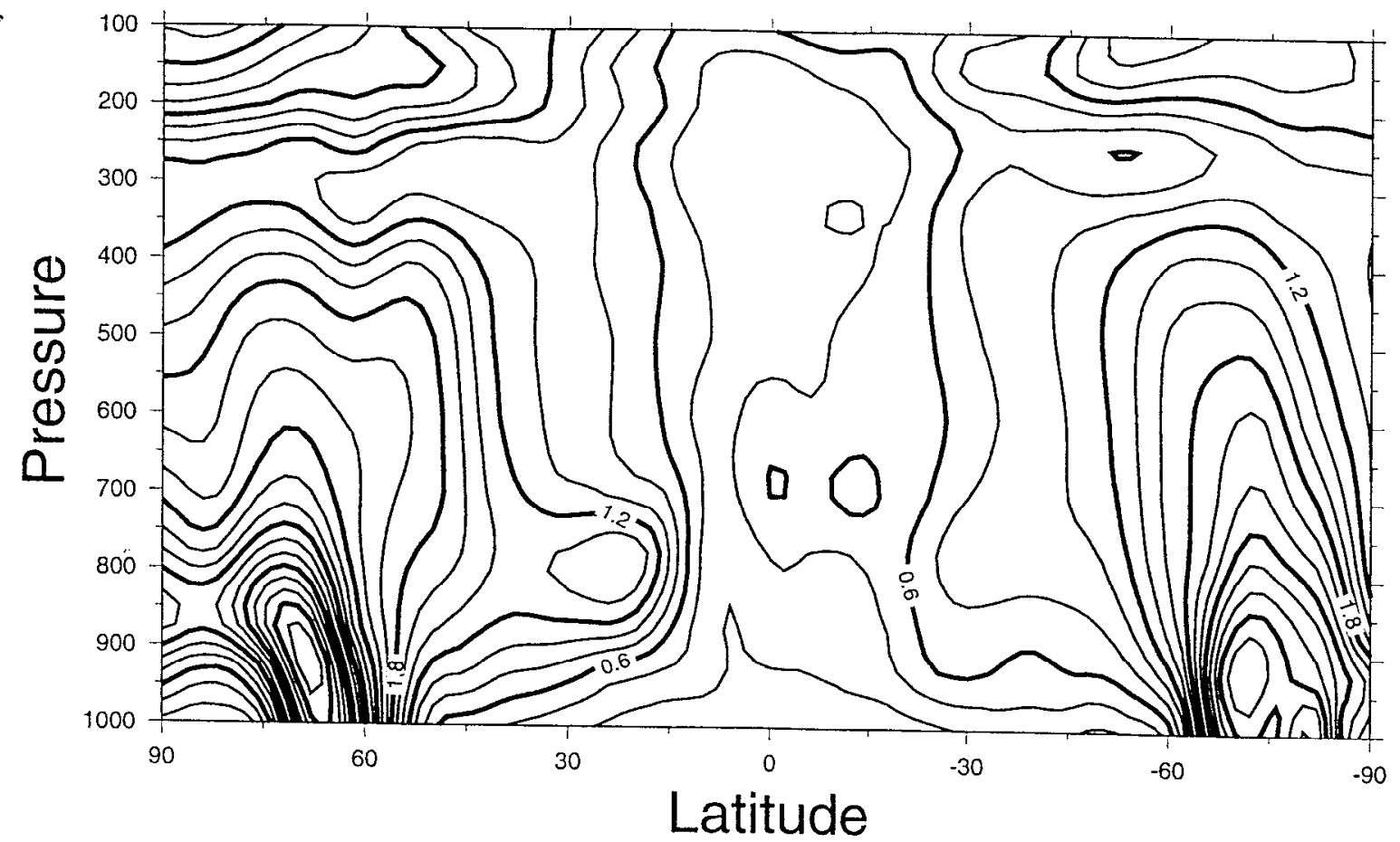

Figure 11. Standard deviation of monthly mean air temperature anomalies along longitude 225E from North to South Pole for the CCM3 using climatological SSTs. Contour interval is $0.15 \mathrm{~K}$ 

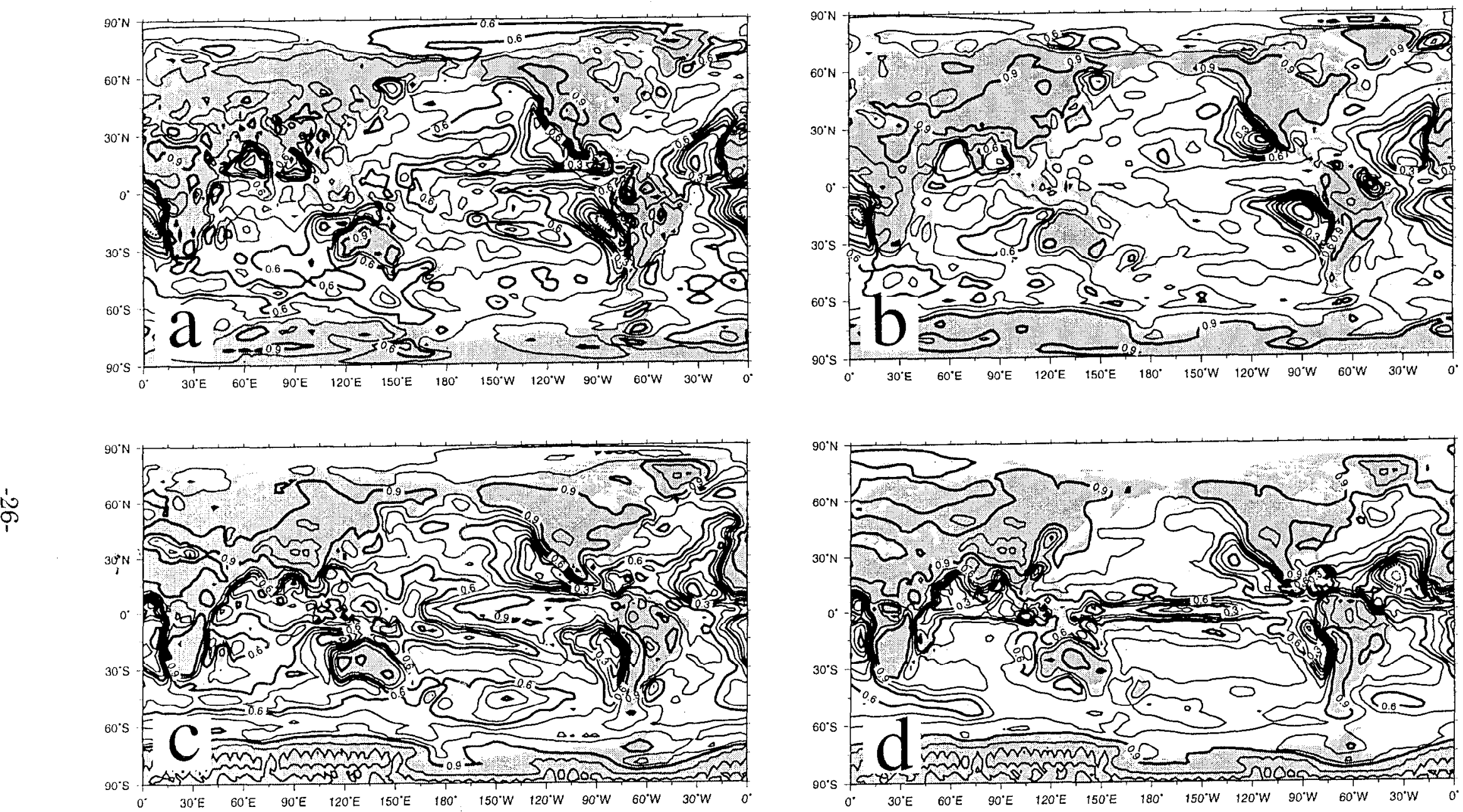

Figure 12. Correlation between monthly mean anomalies of the surface and $850 \mathrm{hPa}$ air temperature. (a) ERA, (b) NCEP/NCAR, (c) CCM3 , (d) CSM. Contour interval is 0.1 

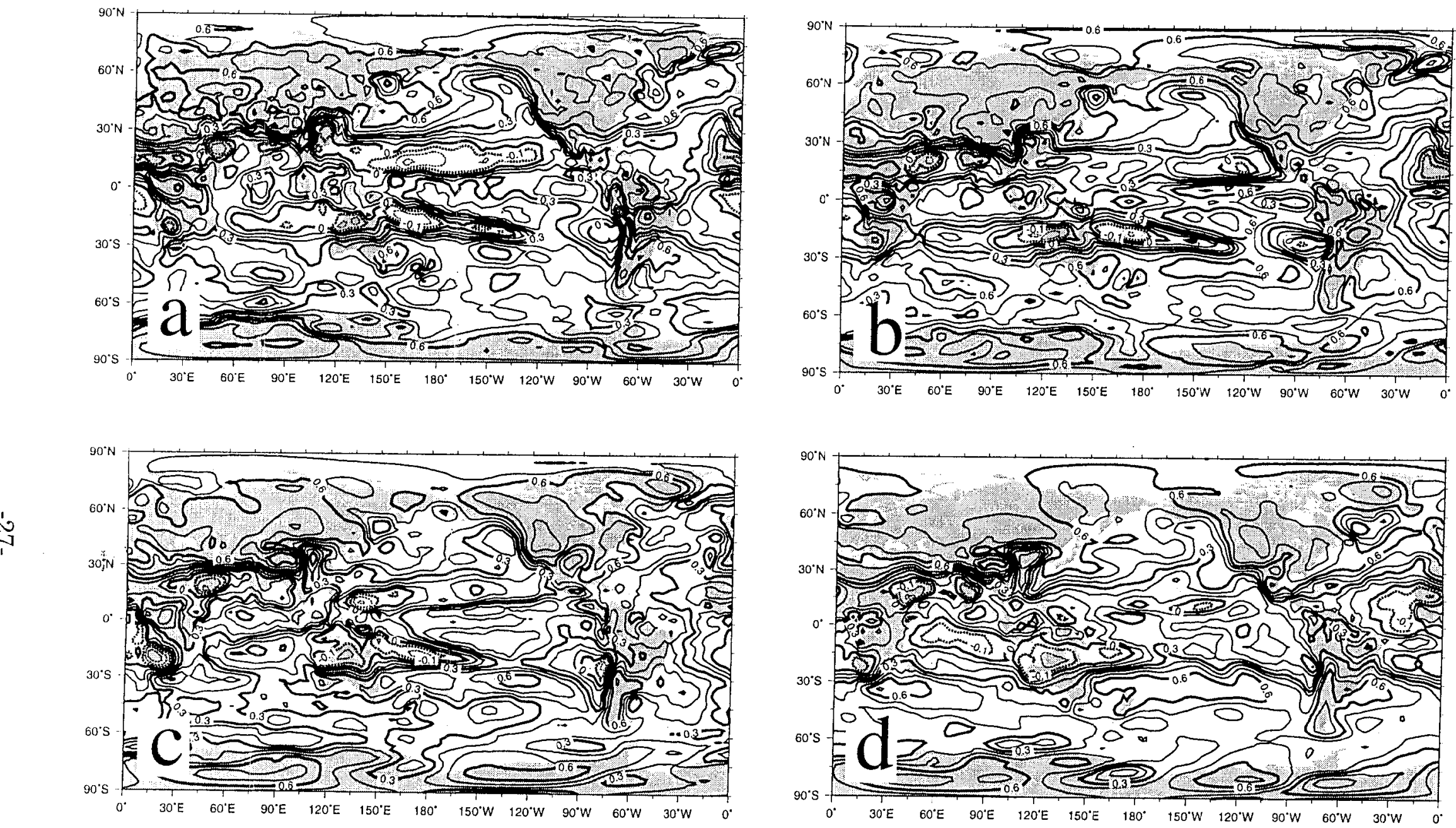

Figure 13. Correlation between monthly mean anomalies of the surface and $500 \mathrm{hPa}$ air temperature.(a) ERA, (b) NCEP/NCAR, (c) CCM3, (d) CSM. Contour interval is 0.1 

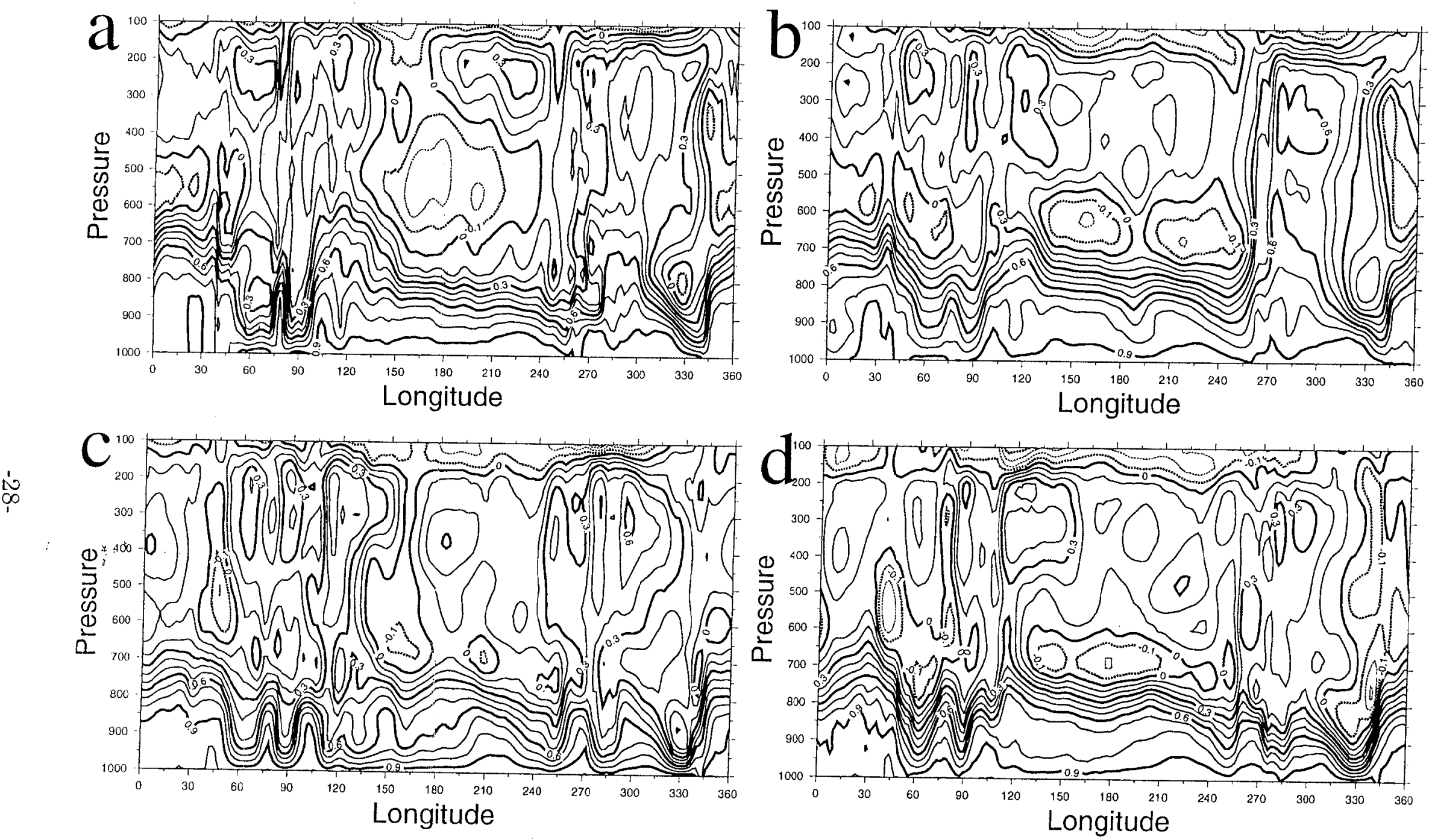

Figure 14. Correlation between monthly mean anomalies of the surface and levels from 1000 to $100 \mathrm{hPa}$ around the globe at latitude $15 \mathrm{~N}$. (a) ERA, (b) NCEP/NCAR, (c) CCM3, (d) CSM. Contour interval is 0.2 . 

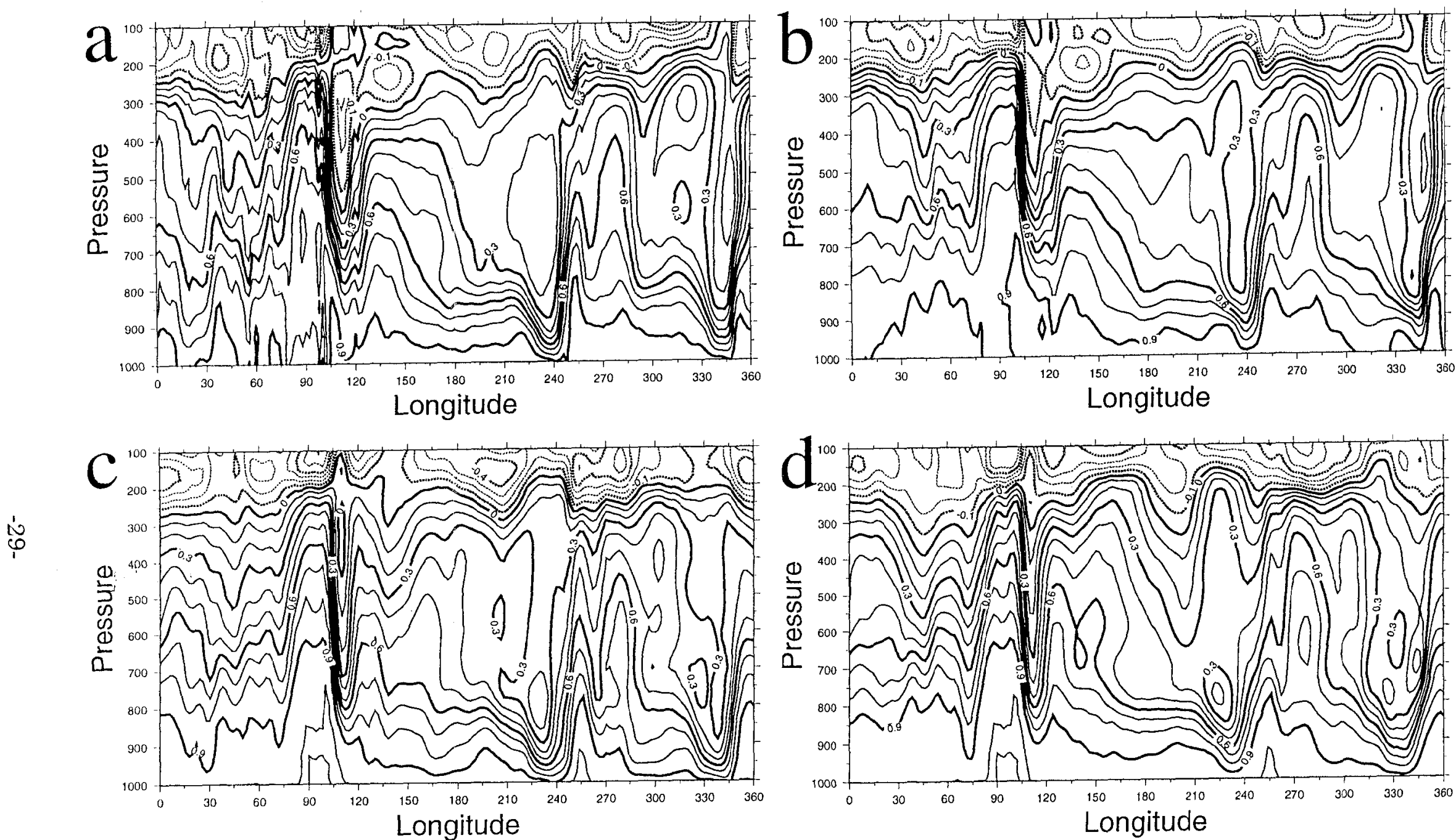

Figure 15. Correlation between monthly mean anomalies of the surface and levels from 1000 to $100 \mathrm{hPa}$ around the globe at latitude $30 \mathrm{~N}$. (a) ERA, (b) NCEP/NCAR, (c) CCM3, (d) CSM. Contour interval is 0.2 . 


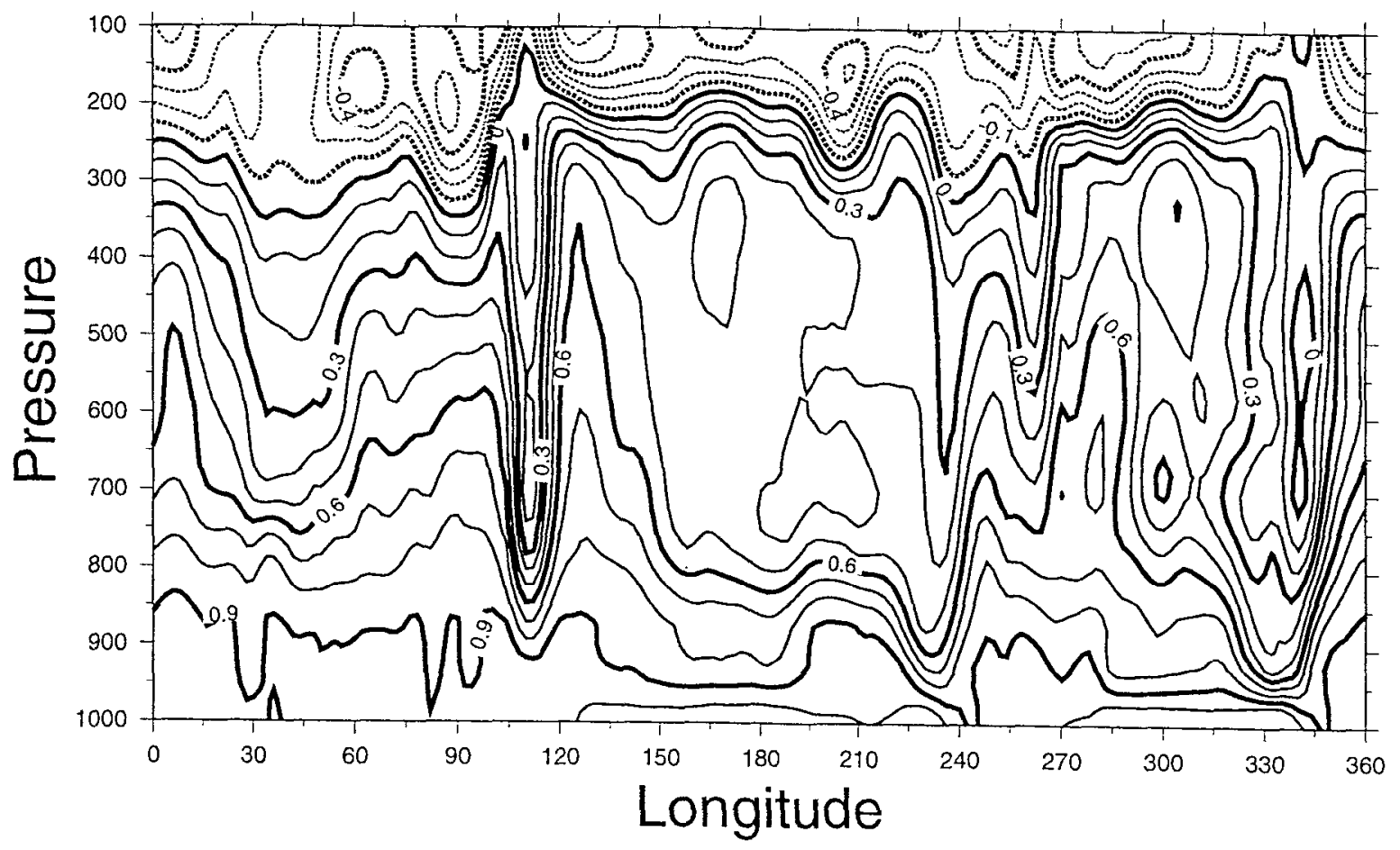

Figure 16. Correlation between monthly mean anomalies of the surface and levels from 1000 to 100 $\mathrm{hPa}$ around the globe at latitude $30 \mathrm{~N}$ forthe CCM3 using climatological SSTs. Contour interval is 0.2. 

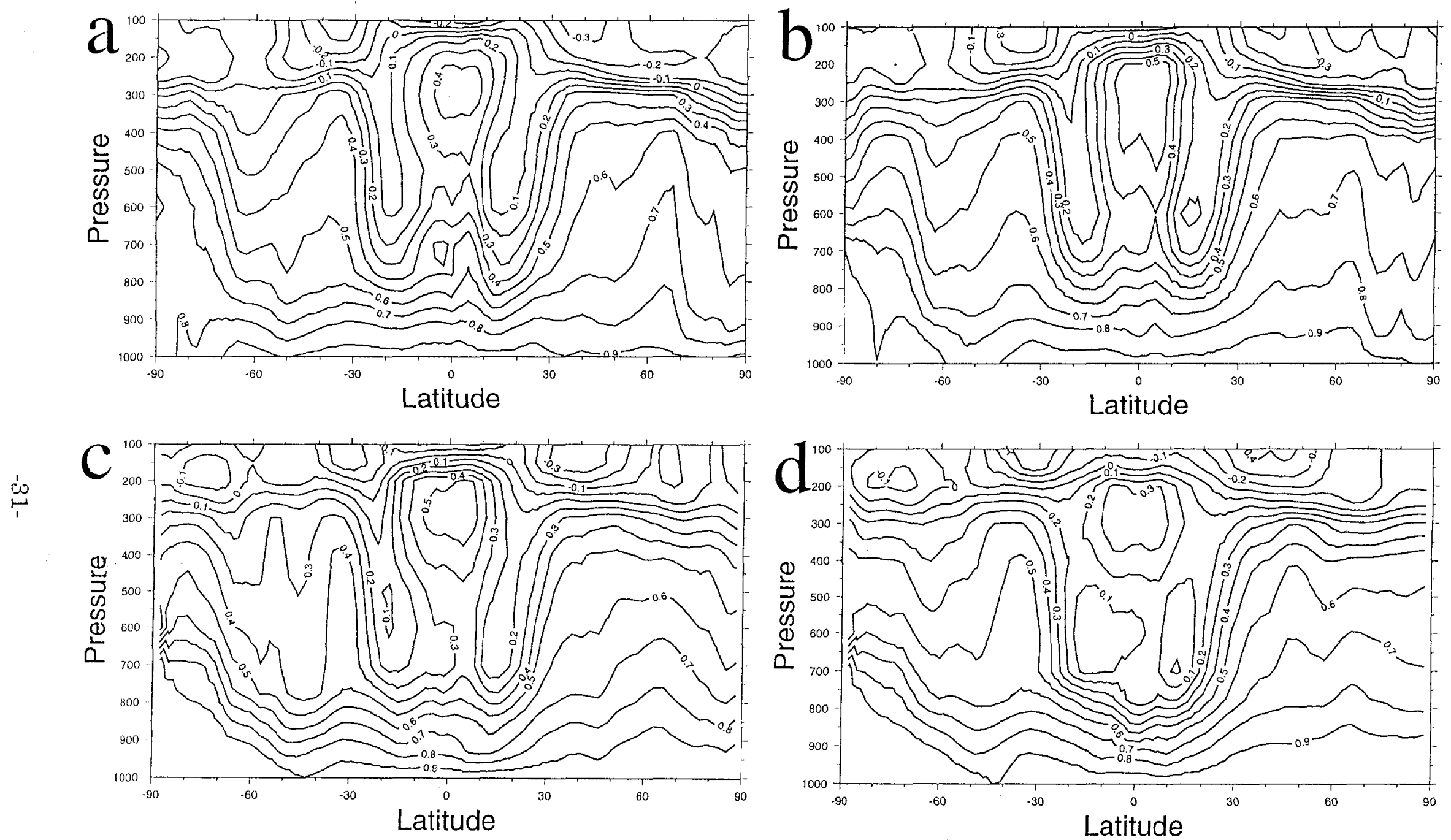

Figure 17. Zonally averaged correlation between monthly mean anomalies of the surface and levels from 1000 to $100 \mathrm{hPa}$. (a) ERA, (b) NCEP/ NCAR, (c) CCM3 , (d) CSM. Contour interval is 0.1 

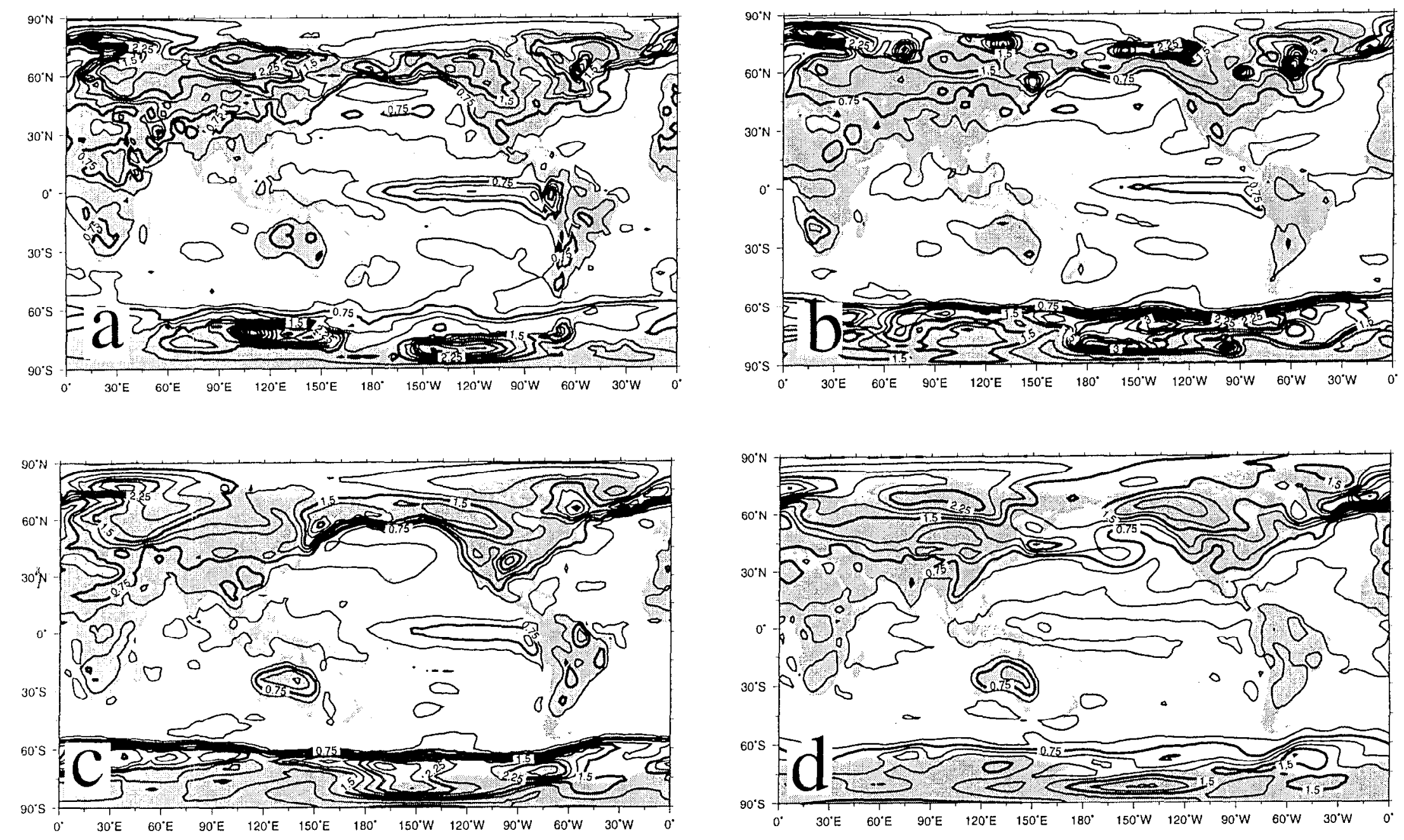

Figure 18. Standard deviation of low pass filtered monthly mean surface air temperature anomalies. The anomalies are defined as deviations from the annual cycle. (a) ERA, (b) NCEP/NCAR, (c) CCM3, (d) CSM, Contour interval is $0.5 \mathrm{~K}^{\circ}$. 

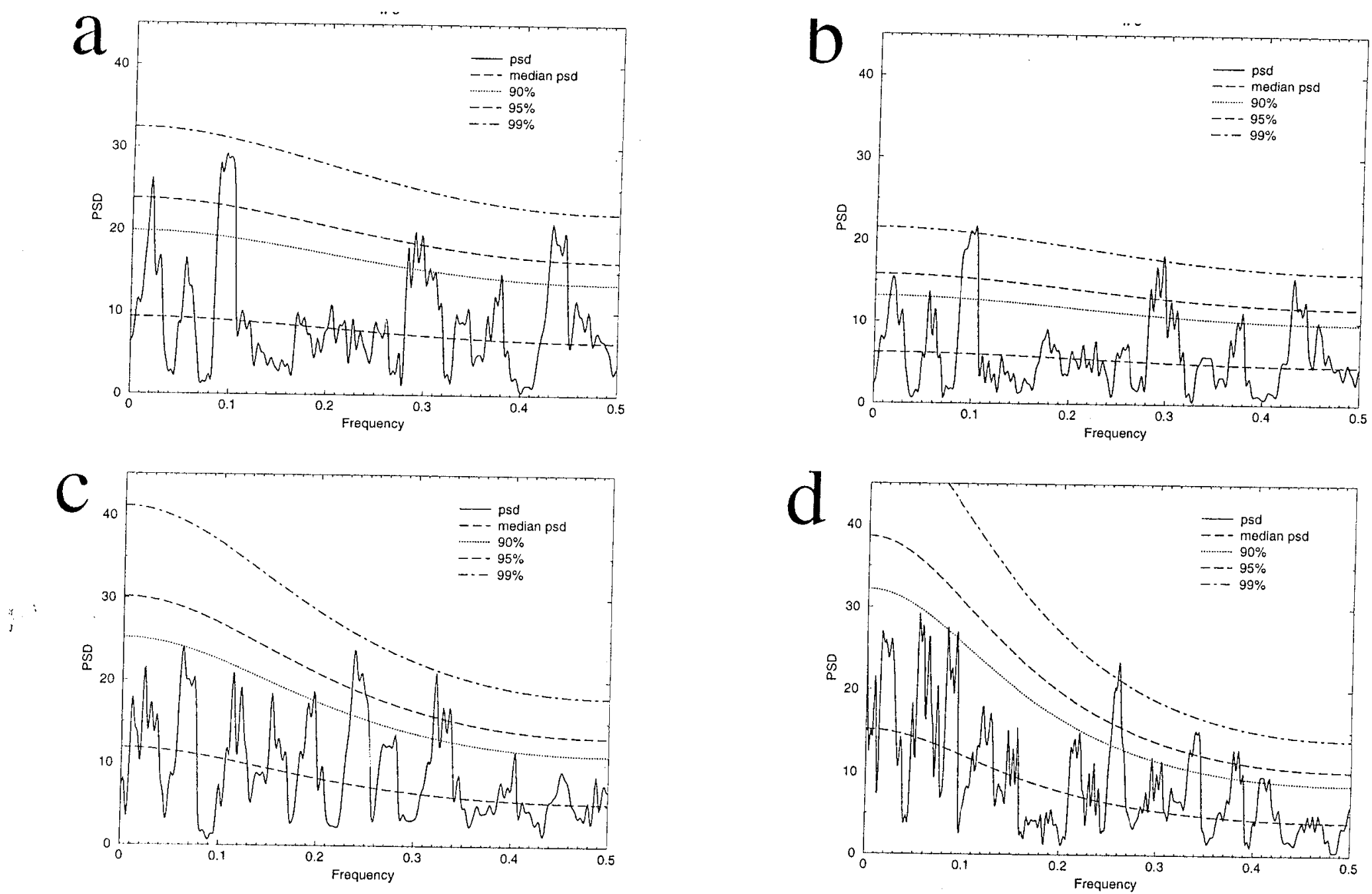

Figure 19. Multitaper spectrum of the monthly surface air temperature anomalies in a region 5 degrees by 5 degrees about $120 \mathrm{~W}, 60 \mathrm{~N}$. . Two tapers were used, yielding a half spectral bandwidth spectral resolution of $0.024 \mathrm{cycles} / \mathrm{month}$. The thin lines indicate the median (50), 90\%, $95 \%$ and $99 \%$ significance levels against a red noise null hypothesis. 

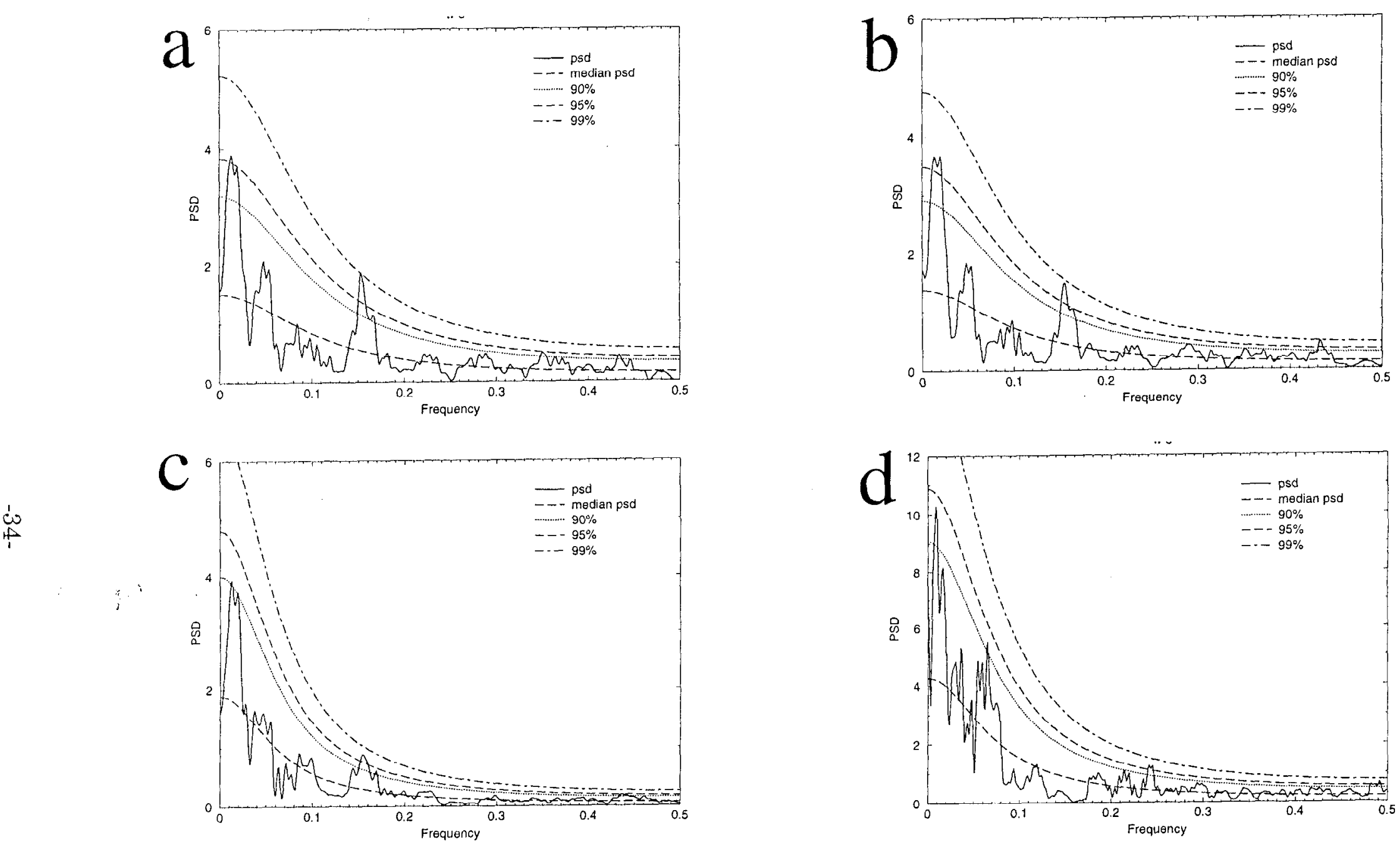

Figure 20. $\Lambda \mathrm{s}$ in Fig. 19, except for a point in the North Pacific, 170W, $45 \mathrm{~N}$. 


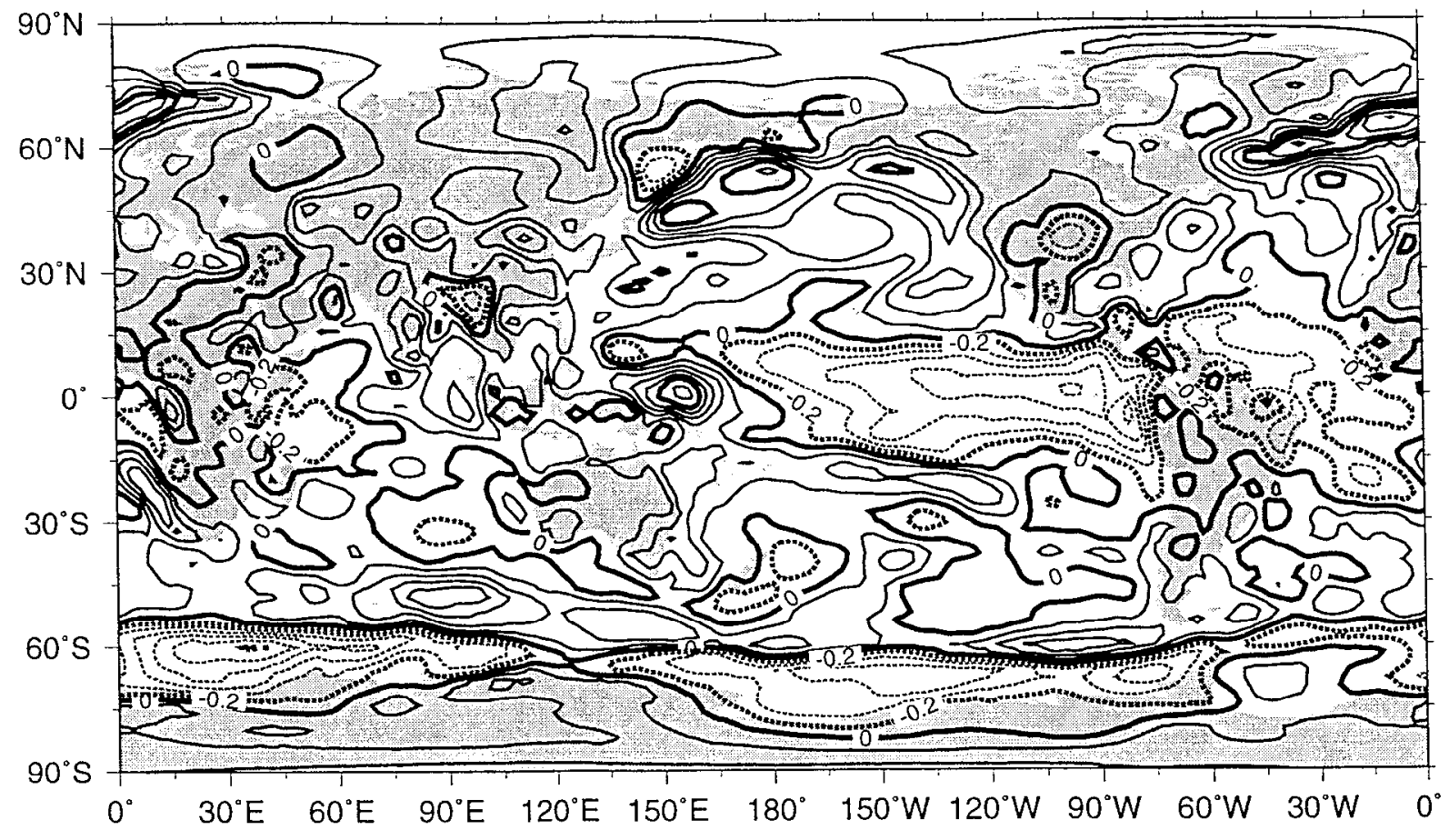

Figure 21. Ratio of the variance for the surface air temperature of the CSM and CCM3 for lowpass monthly mean data. The data are for the 20 years of 16 to 35 for the CSM and the 14 years of CCM3 simulation using observed SST's from 1979 to 1993. 


\section{Figure Captions}

Figure 1. Standard deviation of monthly mean surface air temperature anomalies. The anomalies are defined as deviations from the annual cycle. (a) ERA, (b) NCEP/NCAR, (c) CCM3, (d) CSM. Contour interval is $0.5 \mathrm{~K}^{\circ}$.

Figure 2 as in Fig. 1 except for the $850 \mathrm{hPa}$ level. (a) ERA, (b) NCEP/NCAR, (c) CCM3 , (d) CSM. Contour interval is $0.5 \mathrm{~K}^{\circ}$.

Figure 3 as in Fig. 1 except for the $300 \mathrm{hPa}$ level. (a) ERA, (b) NCEP/NCAR, (c) CCM3 , (d) CSM. Contour interval is $0.15 \mathrm{~K}^{\circ}$.

Figure 4. Standard deviation of monthly mean air temperature anomalies for the CCM3 using climatological SSTs. (a) Surface air, (b) $850 \mathrm{hPa}$, (c) $300 \mathrm{hPa}$. The contour intervals are $0.5,0.5$ and $0.15 \mathrm{~K}^{\circ}$, respectively.

Figure 5. Standard deviation of temperature about the globe at the Equator from 1000 to $100 \mathrm{hPa}$. (a) ERA, (b) NCEP/NCAR, (c) CCM3, (d) CSM. The contour interval is $0.5 \mathrm{~K}^{\circ}$.

Figure 6. Standard deviation of temperature about the globe at $15^{\circ} \mathrm{N}$ from 1000 to $100 \mathrm{hPa}$. (a) ERA, (b) NCEP/NCAR, (c) CCM3, (d) CSM. The contour interval is $0.1 \mathrm{~K}^{\circ}$.

Figure 7. Standard deviation of temperature about the globe at $15^{\circ} \mathrm{S}$ from 1000 to $100 \mathrm{hPa}$. (a) ERA, (b) NCEP/NCAR, (c) CCM3, (d) CSM. The contour interval is $0.1 \mathrm{~K}^{\circ}$.

Figure 8. Standard deviation of temperature about the globe at $45^{\circ} \mathrm{N}$ from 1000 to $100 \mathrm{hPa}$. (a) ERA, (b) NCEP/NCAR, (c) CCM3, (d) CSM. The contour interval is $0.15 \mathrm{~K}^{\circ}$.

Figure 9. Standard deviation of monthly mean air temperature anomalies for the CCM3 using climatological SSTs. Pressure - Longitude sections along (a) Equator, (b) 15N, (c) 15S., (d) 45N. The contour intervals are $0.15 \mathrm{~K}^{\circ}$.

Figure 10. Standard deviation of monthly mean air temperature anomalies along longitude 225E from North to South Pole, (a) ERA, (b) NCEP/NCAR, (c) CCM3 , (d) CSM. Contour interval is $0.2 \mathrm{~K}^{\circ}$

Figure 11. Standard deviation of monthly mean air temperature anomalies along longitude 225E from North to South Pole for the CCM3 using climatological SSTs. Contour interval is $0.15 \mathrm{~K}$ 